\title{
Measuring adoption of industry 4.0 technologies via international trade data: insights from European countries
}

\author{
Davide Castellani $^{1,2}$ (D) $\cdot$ Fabio Lamperti $^{1}$ (D) Katiuscia Lavoratori $^{1}$ (D)
}

Received: 6 September 2021 / Revised: 22 November 2021 / Accepted: 2 December 2021 /

Published online: 10 January 2022

(C) The Author(s) 2022

\begin{abstract}
The investigation of the adoption of Industry 4.0 (I4.0) technologies and its implications, both at the macro and micro level, has attracted growing interest in the recent literature. Most studies have looked at the production and diffusion of related innovations and knowledge, but what do we know about the adoption of these technologies over time and across countries? In this paper, we look at three I4.0 technologies and present a new empirical perspective able to overcome the limitations of existing attempts at measuring their adoption, generally based on small-scale and countryspecific studies. Our study provides a methodology that allows measuring adoption across countries for a relatively long time period. In so doing, we build on the wellestablished idea in the international economics literature that trade of capital goods captures technology diffusion, and so adoption across countries. We provide preliminary and comprehensive evidence on the adoption of these I4.0 technologies in Europe and set the premise for monitoring its evolution and implications on a large scale and over time.
\end{abstract}

Keywords Industry $4.0 \cdot$ Advanced manufacturing technologies $\cdot$ Technology diffusion - Industrial robots · Additive manufacturing · Industrial internet of things · COVID-19

JEL Classifications F1 · F2 · O33 · O34 · O52

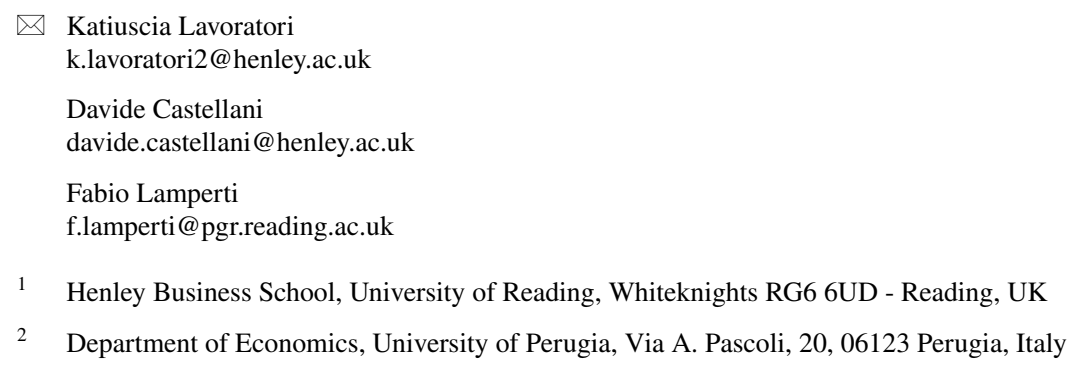




\section{Introduction}

While there is no universal agreement about what an industrial revolution is, there is consensus that three major technological shocks had a substantial impact on the way goods were manufactured throughout history. That is, the introduction of water and steam-powered manufacturing facilities; the electrically-powered technologies enabling mass production; the introduction of Information and Communication Technology (ICT) in the manufacturing process. More recently, governments, industries and academic scholars have highlighted the emergence of a new set of digital (and smart) technologies as the key players of a fourth industrial revolution (4IR) wave, also called Industry 4.0 (Brynjolfsson \& McAfee, 2014; Davies, 2015; Schwab, 2016; OECD, 2017; UNCTAD, 2020; WIPO, 2019). ${ }^{1}$

Within the industrial manufacturing domain, the term Industry 4.0 was coined in 2011 by the German Government to embrace the challenge of revitalising the manufacturing industry and boosting prosperity among developed economies, driven by the adoption and integration of a set of enabling advanced technologies (Kagermann et al., 2013; Mariani \& Borghi, 2019; Rüßmann et al., 2015). In this paper, we will refer to advanced manufacturing technologies (AMTs) as this group of key player technologies driving such changing environment. AMTs are defined as "computercontrolled or micro-electronics-based equipment used in the design, manufacture or handling of a product" (OECD, 2012).

These technologies are seen as able to enhance operational flexibility, production efficiency and quality, and to reduce set-up costs, and so in turn to boost productivity and performance (Büchi et al., 2020; Rüßmann et al., 2015; Schwab, 2016; Skilton \& Hovsepian, 2017), and create the conditions for sustainable operation management among supply chain operators (Lopes de Sousa Jabbour et al., 2018). In addition, they also allow for flexibility and speed in prototyping and responding to unpredictable demand needs and uncertainty. This has become extremely important since consumer needs and, more generally, the economic external environment are more and more volatile. Indeed, the role of technologies under the recent unprecedented circumstance of the COVID-19 pandemic is an inspiring example (The Guardian, 2020; European Commission, 2020; UNCTAD, 2020).

Despite the growing popularity of the matter across policy institutions, media and academic scholars, a clear picture of the adoption of I4.0 technologies on the global economy is still an under-investigated research area. Some evidence is provided using data collected from surveys in specific countries, or looking at specific technologies or on a small number of firms, through case studies (Dachs et al., 2019; Delic \& Eyers, 2020; Sandström, 2016, among others). The main motivation for

\footnotetext{
1 Several initiatives from national governments have taken place worldwide, starting with the 'Advanced Manufacturing Partnership' in the USA and the 'High-tech Strategy 2020' in Germany, followed by 'La Nouvelle France Industrielle' in France, the 'Future of Manufacturing' in the United Kingdom, 'Industria 4.0 ' in Italy, the 'Factories of the Future' as part of the European Programme Horizon 2020 (Liao et al., 2017; Mariani and Borghi, 2019); some, emerging also in developing countries like Morocco (Gallab et al., 2021).
} 
such paucity of evidence is the lack of reliable and precise measures of adoption on a large scale across countries and over time.

Some studies have looked at the production and diffusion of innovation and knowledge associated with the 4IR (Balland \& Boschma, 2021; Benassi et al., 2020; Corradini et al., 2021; Felice et al., 2021; Venturini, 2021), with special reference to the technological and geographical aspects of the origin and diffusion of I4.0 knowledge and innovations (Balland \& Boschma, 2021; Ciffolilli \& Muscio, 2018; Corradini et al., 2021; Martinelli et al., 2021). However, more effort is needed to enhance our understanding of the magnitude and evolution over time, geographical spread across countries and the presence of specialisation patterns in the adoption of I4.0 technologies. This becomes extremely important for understanding a relatively new phenomenon and to provide suggestions both for policymakers and managers that are dealing with such technological changes.

From a methodological perspective, tracking the growth and evolution of emerging technologies is particularly complicated since there are no available data, especially when the transformation is still ongoing and the technology is not mature. Our empirical approach addresses this problem by relying on the well-developed idea that cross-country technology transfer can occur via international trade of capital goods.

In a seminal work, Caselli and Coleman (2001) investigate the technology diffusion of computers in the $70 \mathrm{~s}-80 \mathrm{~s}$. At that time, computers represented a revolutionary innovation and a direct measure of capital investments was not available on a large scale. As an embodied technology, computers are an ideal case of technology diffusion to investigate, and as the authors do remark "technology diffusion takes place through imports of the equipment embodying the technology" (Caselli \& Coleman, 2001, p. 328). Inspired by their intuition, we measure adoption of AMTs with import flows of selected products and machinery that embody such technologies, and we corroborate this measure with the use of production data able to capture the component of adoption, related to domestically produced goods. The idea of using imports as a proxy of technology adoption and diffusion has been developed in the literature (e.g. Acemoglu \& Restrepo, 2018; Caselli \& Wilson, 2004), and since these technologies belong to complex and high value categories of capital goods, the problem concerning re-exporting activities of imports in the form of intermediate inputs is very unlikely (Bernard et al., 2015).

In a nutshell, our methodology consists of identifying the fine-grained (8-digit) product codes of capital goods related to advance industrial robots (AIRs), additive manufacturing (AM) and industrial internet of things (IIoT), i.e. the three capital-embodied AMTs will we focus on. Based on these product codes, we can quantify the adoption of these technologies for 28 European countries over the 2009-2018 period. Our evidence suggests that the most advanced European economies have been investing in these technologies over the years with different degrees and technology specialisation. Interestingly, we also uncover a growing presence of a cluster of Central and Eastern European countries as I4.0 adopters. Two reasons can explain this finding: first, national industrial policies are massively supporting the adoption of such technologies to sustain long-term international competitive advantages; second, the increasing participation of these countries in global value chains (GVCs) facilitates the multinational enterprise 
(MNE) transfer of sophisticated production technologies to their foreign subsidiaries through imports of capital goods or encourages local suppliers to adopt advanced technologies in their production processes.

The main contribution of this work resides in moving forward the conversation about the adoption of AMTs within the I4.0 context, by introducing and improving an empirical measure able to capture the phenomenon. We provide prima facie empirical evidence of the diffusion of AMTs across European countries over the period 2009-2018. At the same time, we provide a discussion about possible extensions of such methodology at the industry and firm level, alongside a further research agenda.

The paper is organised as follows. The next section briefly describes the advanced manufacturing technologies under investigation. Section 3 describes the data and the methodology employed to create the measure of adoption and to identify AMTs from trade data. Section 4 provides an empirical application of the proposed methodology illustrating the relevance, evolution and geographical diffusion of AMT adoption across European countries. Section 5 concludes, summarizing the main findings and proposing possible research directions.

\section{Defining advanced manufacturing technologies}

As discussed in the previous Section, I4.0 gathers a heterogeneous set of technologies, bearing different levels of mutual complementarity as well as different degrees of relatedness with specific industrial operations. These underlying similarities and differences, together with the characteristics of each I4.0 technology, motivate our focus on those technologies that have the highest potential impact in advanced manufacturing processes. Keeping this as our starting point, we embrace the definition provided by the European Foundation for the Improvement of Living and Working Conditions, which identifies five 'game-changing technologies', namely, advanced industrial robots (AIRs), additive manufacturing (AM), industrial internet of things (IIoT), electric vehicles and industrial biotechnologies (Eurofound, 2018). As anticipated, this paper focuses on the first three technologies given their potential to impact significantly all manufacturing sectors to the core of their operations, being part of the I4.0 wave.

Moreover, these are embodied technologies, so that their adoption requires a physical installation of a specific type of capital equipment. This is a crucial distinction concerning other new digital technologies of the 4IR (e.g. artificial intelligence, machine learning, cloud computing, big data, etc.), whose physical component of the technology is usually standardised and multi-purpose (Foster-McGregor et al., 2019). In turn, this further intrinsic feature of the three AMTs we investigate makes them more appropriate for the methodology that we are devising in this paper.

\subsection{Advanced industrial robots (AIRs)}

This category includes advanced industrial robots, which leverage high-level and dynamic programming (i.e. able to perform 'smarter' tasks) and enable more flexibility in production (Eurofound, 2018). Thanks to the falling cost of hardware and 
software experienced during the last decade, there has been a huge improvement in the technical features of industrial robotics. Advanced robots existing nowadays can perform a wider set of tasks compared to their predecessors, especially those requiring high flexibility and accuracy. The possibility of equipping robots also with advanced sensors and functionalities, and the potential for human-machine interactions has enabled their adoption to spread from traditional sectors of usage (e.g. automotive and electronics) to several others (e.g. agriculture and logistics).

\subsection{Additive manufacturing (AM)}

The International Organization for Standardization (ISO) defines additive manufacturing as "the general term for those technologies that based on a geometrical representation creates physical objects by successive addition of material" (ISO, 2015). Currently, these technologies are used for various applications in the engineering industry, but also in other areas such as medicine, architecture, education, and several handcrafted segments (Wohlers Associates, 2014). This category includes highly flexible and adaptable machinery leveraging on digital production technique enabling reduced material consumption and wastes as compared to 'traditional' subtracting methods (Achillas et al., 2015; Atzeni \& Salmi, 2012; Chekurov et al., 2018; Tuck et al., 2008), technically enhanced and highly customised products (Atzeni \& Salmi, 2012; Diegel et al., 2010; Khorram Niaki \& Nonino, 2017; Mellor et al., 2014; Petrick \& Simpson, 2013), as well as fewer manufacturing steps, especially reducing assembly operations (Cuellar et al., 2018; Sandström, 2016; Singamneni et al., 2019; Weller et al., 2015). Additive manufacturing (also referred to as $3 \mathrm{D}$ printing) techniques work by following a reversed logic than traditional manufacturing processes (Attaran et al., 2017), adding or melting subsequent 2D layers of material to generate the final product. Already implemented in the production of plastic consumer products, aerospace and human prosthetics, additive manufacturing is increasingly adopted in other manufacturing sectors (EIB, 2019; Laplume et al., 2016; OECD, 2017).

\subsection{Industrial Internet of Things (IloT)}

The Industrial Internet of Things is used to identify the industrial specializations of the Internet of Things (IoT). The latter consists of " a global infrastructure for the information society, enabling advanced services by interconnecting (physical and virtual) things based on existing and evolving interoperable information and communication technologies" (ITU, 2012). This category includes wireless (and not) sensors, actuators, control and regulation systems, microchips and distributed systems such as Near Field Communication (NFC) chips, Radio-Frequency Identification (RFID) tags and Global Positioning Systems (GPS) (Atzori et al., 2010; Gubbi et al., 2013). IoT systems can be applied to several different contexts to create smart environments (e.g. smart cities, smart homes, smart factories, smart vehicles, etc.). Specifically, Industrial IoT refers to the creation of a digital environment in which (1) controlling machines (i.e. computers), (2) process machinery (e.g. 'traditional' 
automatic manufacturing stations, additive manufacturing machines and industrial robots) and (3) smart products (i.e. products incorporating an RFID tag, NFC chip, GPS or alike systems) are all connected. Hence, IIoT integrates a high-level processing and communication potential able to elaborate huge data amount, collected and transferred between each node of a widespread, seamless network (Atzori et al., 2010; Gubbi et al., 2013). In turn, this creates opportunities for enhanced working conditions, more flexible operations and digital integration along the value chain (Stock \& Seliger, 2016; Wang et al., 2016a; b).

\section{Data and methodology}

\subsection{Building measures of $\mathbf{I} 4.0$ technology adoption}

So far, the empirical literature has been strongly limited by the absence of an extensive, precise and comprehensive measure of adoption to capture such a complex phenomenon, across technologies, across countries and over time.

In particular, some evidence comes from data collected through surveys in specific countries or looking at specific technologies. For instance, data collected by the European Investment Bank (EIB, 2019) and from Eurostat (Eurostat, 2021) provide cross-country insights from a representative sample of firms adopting various technologies of the 4IR - at the aggregate and sectoral level, respectively, at the same time providing only cross-sectional evidence. Conversely, survey data providing insight at a finer level—cross-country, sectoral, or even firm-level adoption-are available either for long time-series although focusing on single technologies (like industrial robots in the case of data from the International Federation of Robotics (IFR)) or for more technologies but on a shorter period (such as for data from the European Manufacturing Survey (EMS) ${ }^{2}$ ). Alternatively, several contributions have addressed the implications of adopting I4.0 technologies directly, through case studies based on specific sectors or a small number of firms (Khorram Niaki \& Nonino, 2017; Sandström, 2016), by small-scale firm-based surveys (Delic \& Eyers, 2020; Kianian et al., 2016), or by extrapolation from alternative sources (Ancarani et al., 2019). In turn, these limits associated with the existing data sources hamper the comparison across countries and sectors, as well as across technologies. We aim at overcoming such data and methodology limitations.

Drawing from Caselli and Coleman (2001), we create two measures as a proxy of adoption: first, we measure adoption by the import of AMT capital goods, using bilateral trade data at the finest level of disaggregated product classes. However, we acknowledge that imports may underestimate adoption in countries that have a large local production of AMTs. To assess the extent of this potential measurement issue, we also resort to a different measure of adoption, which we call net consumption, based on the formula: netconsumption $=($ production + import - export $)$. In this way, we can account for both sources of capital investments determining adoption of

\footnotetext{
${ }^{2}$ See Dachs et al. (2019) for a recent application.
} 
AMTs, that is domestic and foreign production. This second measure is not available for all countries and technologies considered, as production data on goods embodying AMTs are in some cases missing or not reliable. Therefore, this measure is mainly used to validate our import measure of AMT adoption, which is more widely available (also outside the EU) and thus allow us to extend the application of this methodology.

After completing the data collection on trade and production information, we create these adoption proxies for each of the three AMTs we look at (i.e. AIRs, AM and IIoT). First, we compute import variables by creating three 'synthetic' measures computed as the sum of all 8-digit product codes relating to the same technology (as illustrated in detail in Sect. 3.3), for each country-year observation in our EU28 sample. Following the same logic as for the import variables, we build our second proxy measuring adoption (i.e. the net consumption variables) by combining import, export and production data for each AMT.

We finally adjusted values for PPP and converted them in constant 2011 USD using exchange rates and PPP conversion factors from Eurostat and the World Development Indicator (WDI) data set of the World Bank, respectively, so to allow for intertemporal and geographical comparison and to filter out cross-country differences in prices.

\subsection{Data}

We rely on two main sources of data to generate measures of AMT adoption. First, we use highly disaggregated trade data collected from the Comext data set, available on the Eurostat website. Comext provides statistics on the value of goods traded between the EU28 member states (i.e. intra-EU trade) and traded by the EU member states with non-EU countries (i.e. extra-EU trade) (Eurostat, 2019). Goods are classified according to the Combined Nomenclature $(\mathrm{CN})$ classification, which is based on the harmonised Commodity Description and Coding System (HS). The HS provides information up to the 6-digits level of commodity disaggregation, and then the $\mathrm{CN}$ builds on the HS by adding a further breakdown at the 8-digit level. This extension allows us to consider around 9,500 8-digit product codes, which are subject to annual revisions that ensure the $\mathrm{CN}$ to be up to date to changes in technology or patterns of international trade (Eurostat, 2019). ${ }^{3}$ As our interest lies in the identification of very specific capital goods associated with three technologies, the use of 8-digit disaggregated data provides the insight needed to identify with a sufficient deal of precision those product categories in which it is more likely that these AMTs are traded.

Second, we use production data from the PRODCOM data set (Eurostat, 2018) to provide further detail to our analysis and build a measure of net consumption. The PRODCOM data set provides information on the value of goods produced and sold in EU28 countries. Differently from the data reported in Comext, PRODCOM data

\footnotetext{
${ }^{3}$ Data included in the Comext data set are converted in Euros for reporting purposes by Eurostat and expressed in current prices.
} 
follow the Classification of Products by Activity (CPA). As in the case of the CN classification, the CPA is revised every year and consists of around 3,900 products; hence, one CPA product may correspond to one or more $\mathrm{CN}$ goods (even though in the case of some product categories the CPA features a higher level of detail as compared to the $\mathrm{CN}$ ). Furthermore, the CPA classification differentiates itself from the $\mathrm{CN}$ one as it is based on the NACE Rev.2 classification. This means that the first 4-digits of each product code in the CPA corresponds to the 4-digit sector in which the product is manufactured.

Both Comext and Prodcom databases also report data on quantities of 8-digit products, traded and produced. Though quantities would represent a more desirable measure as they are not affected by inflation dynamics or conversions for international and intertemporal comparison, our preferred measures are based on value data. There are two main reasons for this choice: first, quantities are frequently reported in different ways in the two data sets, ${ }^{4}$ thus not allowing for comparison on the quantities of all product categories we look at. Second, data on quantities present a high share of missing values in our country-year observations for many of the disaggregated product codes we consider. Hence, we decided to employ value data as they enable higher comparability across the two sets of data. Data were collected in 2019 using the latest HS classification (i.e. HS-2017) and the corresponding versions of the $\mathrm{CN}$ and CPA classifications as reference.

\subsection{Identifying AMTs via trade data}

Our identification of the specific types of machinery, equipment and components related to AMTs starts from the analysis of several sources of information. In particular, we relied on (i) the relevant engineering literature both from the practitioner-for instance, the standard international terminology approved by ASTM International (2013) and ISO (2015) for AM technologies, concepts and definitions on IIoT provided by ITU (2012) — and an academic point of view; (ii) product catalogues of representative producing firms for AIRs, IIoT and $\mathrm{AM}^{5}{ }^{5}$ (iii) the World Customs Organisation (WCO) and (iv) Eurostat. ${ }^{6}$ From these sources, we were able to develop a list of keywords related to our AMTs of interest. This keyword-based approach has been widely used lately, and applied to different data sources-e.g. patents, business registers, scientific publications, trade and industrial records (Craglia et al., 2018; De Prato et al., 2019; Van Roy et al., 2019). The list of identified keywords is reported in Table 5 in Appendix B.

\footnotetext{
${ }^{4}$ For instance, in Comext, quantities are usually reported in $100 \mathrm{~kg}$, while in PRODCOM are reported in different units such as $\mathrm{kg}, \mathrm{m} 2$ or number of items.

5 Given its wider discussion in the existing literature (e.g. Acemoglu and Restrepo, 2018), the identification of the relevant nomenclature is a lesser problem in the case of AIRs; hence, as a reference, we looked at ABB Ltd product catalogue. Concerning AM, we looked at product catalogues from three main producers worldwide, namely Stratasys Ltd., 3D Systems Inc. and EOS GmbH. Finally, relatively to IIoT, given that it is the technology bearing the widest set of capital goods among the technologies we focus on, we consulted product catalogues from Intel Corp., ABB Ltd., Siemens AG, Hewlett Packard Enterprise LP, Bosch GmbH, GE Digital Plc., Cisco System Inc. and Rockwell Automation Inc.

${ }^{6}$ For more details, see https://trade.ec.europa.eu/tradehelp/classifying-computers-software.
} 
The identified keywords were then used to define an initial list of 258 -digit $\mathrm{CN}$ product codes. ${ }^{7}$ We acknowledge that some of the technologies we focus on may be embedded also in other product classes not included in our shortlist. However, we adopt a conservative approach that allows us to consider only those product codes reporting a precise, coherent and unquestionable description, and to underestimate rather than overestimate the phenomenon. At the same time, the selected keywords might also lead to false-positive results or matches with product codes at a lower level of disaggregation (e.g. 6- or 4-digit codes). Hence, we performed a second stage of manual screening in which we exclude potential false-positive matches and identify the relevant 8-digit codes included in the less disaggregated categories matching with our keywords. More specifically, we focus on trade in capital goods of product codes included in the 4-digit CN codes 8463 (Machine tools for working metal or cermets, without removing material), 8471 (Automatic data-processing machines and units thereof [...]), 8477 (Machinery for working rubber or plastics or for the manufacture of products from these materials), 8479 (Machines and mechanical appliances having individual functions), 8515 (Electric, laser or other light or photon beam, electron beam [...] machines and apparatus for hot spraying of metals or cermets), 8517 (Apparatus for the transmission or reception of voice, images or other data, including apparatus for communication in a wired or wireless network [...]), 8526 (Radar apparatus, radio navigational aid apparatus and radio remote control apparatus), 8542 (Electronic integrated circuits) and 9032 (Automatic regulating or controlling instruments and apparatus). The full list of product codes initially identified and the related descriptions are reported in Table 6 in Appendix B.

In the case of AIRs, our initial research brought to the identification of a single, main, code-since we do not aim at considering other forms of more traditional automation like non-robotics handling machines or conveyor belt systems. The other two cases present more challenges: specific codes for AM machines and IIoT devices do not yet exist in either the HS or the CN classifications. In the case of AM, the World Customs Organisation recognises the lack of a specific chapter in the HS classification encompassing these types of machinery, thus resulting in their categorisation being spread in several other product codes (Yuk, 2018). To the best of our knowledge, the identified codes are those most suitable to be used in practice and reflect the specific characteristics of the existing AM processes, as described above. The case of IIoT is even more challenging as the variety of devices is larger than in the case of AM, and cases of our focus goods being matched to a wider set of product categories greatly increases. Nonetheless, based on further validation discussed below, we believe the set of codes shortlisted here should capture much of the trade associated with IIoT components as product descriptions of the shortlisted goods refer to very specific products, classified in a highly detailed way.

To validate the selection process for the shortlisted $\mathrm{CN}$ codes, we first developed a survey to collect information on the $\mathrm{CN}$ (and/or CPA) product codes used by producers of the three AMTs when exporting (and/or producing) their products. Then, we consulted experts and practitioners from the Italian Customs Agency and a private customs broker.

\footnotetext{
7 We define the product categories of interest starting from CN-2017 classification (that following the latest revision of the HS classification, HS-2017).
} 
Overall, the 8-digit codes originally identified were confirmed and, at the same time, no initially shortlisted code was discarded, hinting to the goodness of the overall identification procedure. Appendix A provides further details on the validation process.

After the validation process, we matched the $25 \mathrm{CN}$ codes considered in Table 6 with 26 codes in the CPA nomenclature, according to the 2017 correspondence table provided by Eurostat. Since a crucial task for our analysis lies indeed in the identification of the correct product codes associated with our AMTs, when looking at past and subsequent years, we use year-to-year correspondence tables provided by Eurostat, and first we checked for forward and backwards changes that occurred in each of the two classifications along the period considered (2009-2018); second, we cross-checked the correspondence between the $\mathrm{CN}$ and the CPA classifications yearby-year to track any potential change related to the identified codes.

Changes in the $\mathrm{CN}$ and CPA classifications are of two types: (1) new products are added to the classifications with new codes; (2) existing product codes are converted into new product codes. Changes of this second type are problematic, as they might imply not just the 'recoding' of certain products but also the elimination of 'old' product codes, whose related products are then absorbed in one (or more) new codes. Specifically, in cases in which multiple $\mathrm{CN}$ codes correspond to one or more CPA codes (or vice versa), as well as for cases in which the classification has changed over time, we followed the methodology by Van Beveren et al. (2012). This methodology proceeds by creating 'synthetic' codes by grouping together the codes which are subject to changes. In this way, we ensure full consistency in the correspondence between trade and production data over time.

When looking at the product codes we have identified as capturing AMTs, this procedure resulted in the reduction of our product codes from 25 to 22 following the $\mathrm{CN}$ nomenclature, and from 26 to 20 following the CPA nomenclature. Our crosschecking procedure highlighted a mostly consistent correspondence of the product codes, across both years and classifications, with only a few cases in our list of codes subject to either type (1) or type (2) changes. Table 1 reports the correspondence table between CN and CPA codes, in 2017.

\section{Discussion of finding}

In this Section, we present the main trends over time and across countries characterising the diffusion of AIRs, AM and IIoT across EU28 countries, between 2009 and 2018. The choice of focussing on the period after 2009 is driven by the following considerations. In 2006 the German government has launched the High-Tech Strategy to drive innovation actions and technological innovation. In 2009, after the global financial crisis, the demand for mechanical engineering products returned to normal (Kagermann et al., 2013). In the same year, Korea has launched a fiveyear plan to encourage $\mathrm{R} \& \mathrm{D}$ investments in the intelligent robot industry aiming at expanding the adoption of industrial robots in other industrial sectors, since industrial robotics can be considered the first key technological driver (De Backer et al., 2018). Furthermore, several core patents protecting additive manufacturing technologies, such as fused deposition modelling and selective laser sintering, expired 


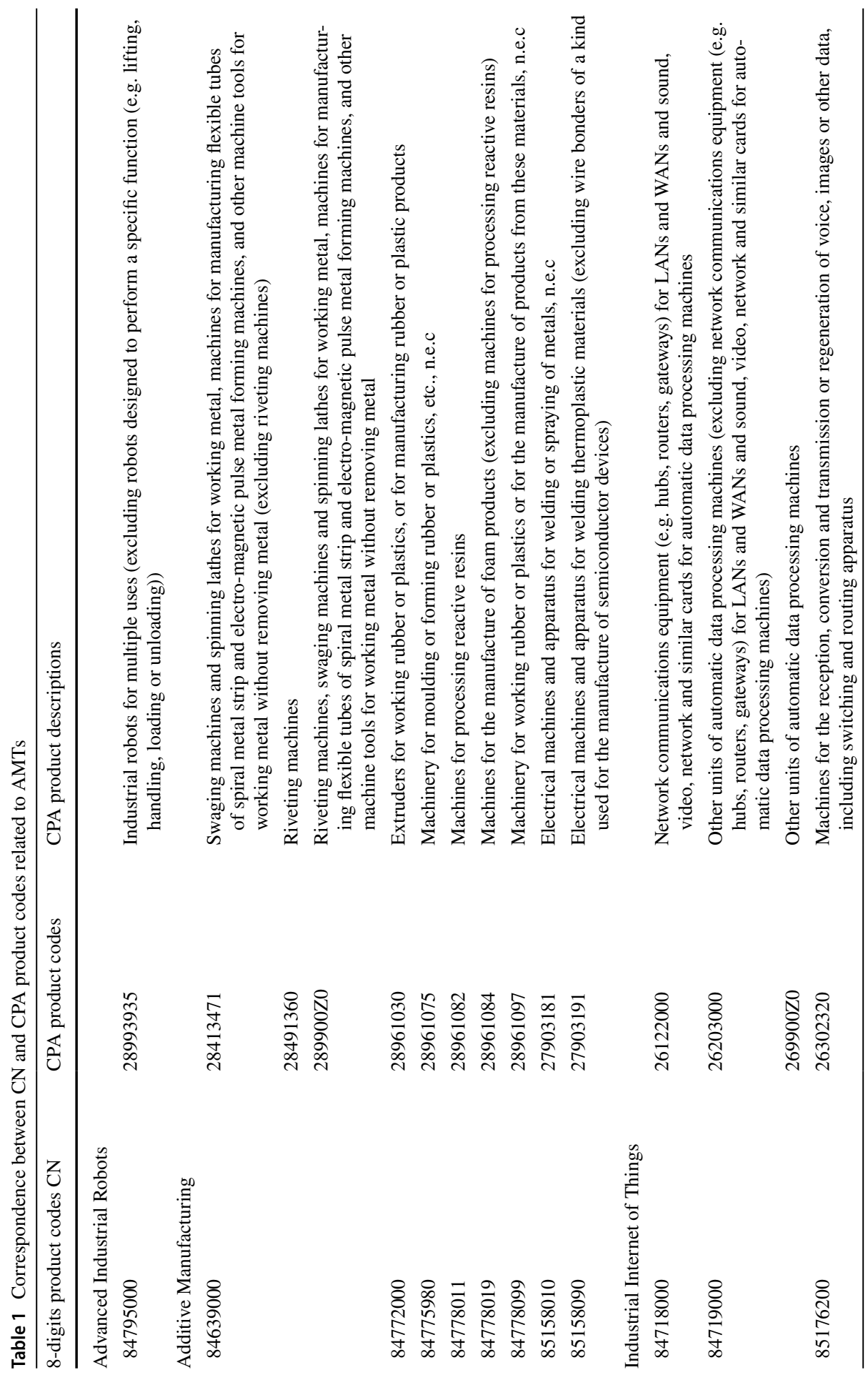




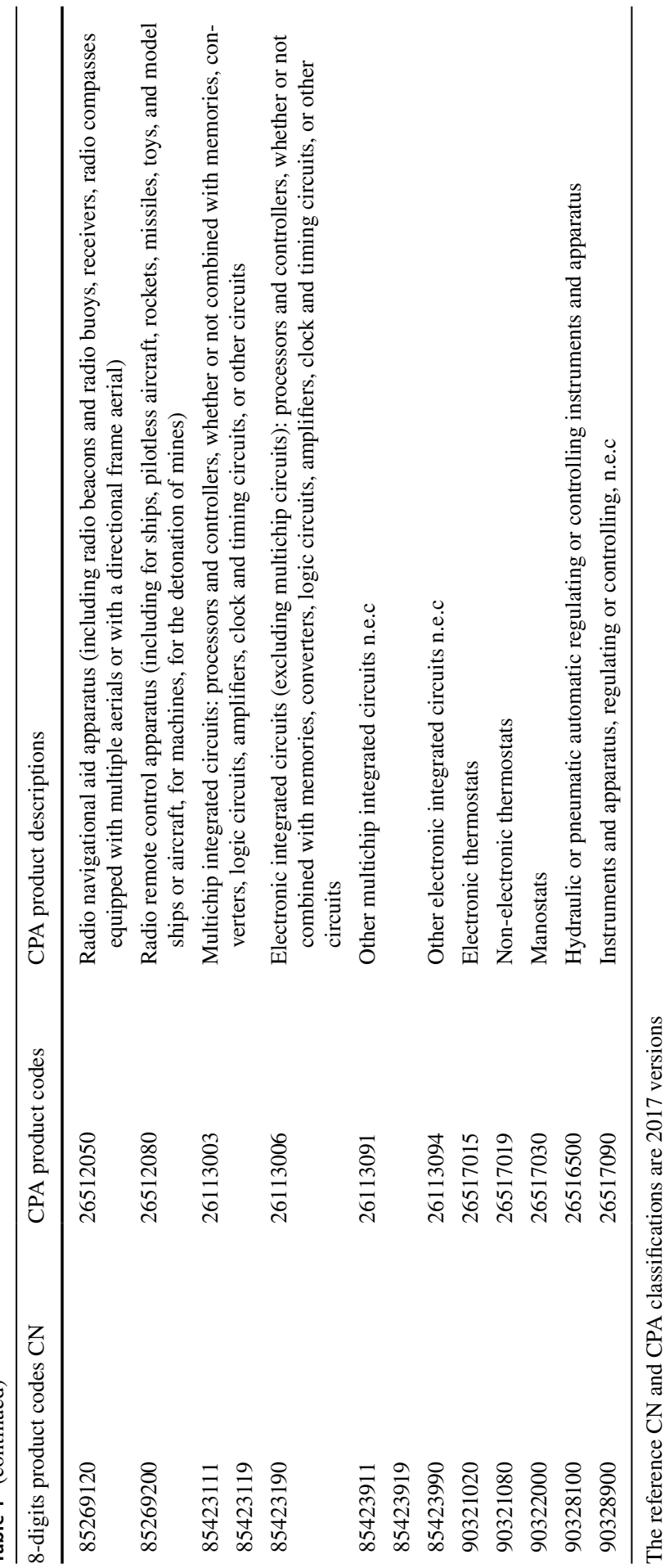


between 2009 and 2014 (Laplume et al., 2016). This created the right conditions for many new producers of additive manufacturing machinery to start their business about spill-over inventions (Wohlers Associates, 2014). Thus, we start the period of observation from 2009, which can be reasonably recognised as the beginning of a global ferment on this technological wave.

\subsection{Preliminary insights on AMT adoption}

Our first focus is on the relationship between import and net consumption measures in our EU28 sample, over the 2009-2018 period. This relationship can be explored only on the subsample of countries for which production data are available for the product codes described in Sect. 3; hence, for which net consumption can be computed.

Rooting our argument in the literature on technology diffusion (e.g. Acharya \& Keller, 2009; Caselli \& Coleman, 2001; Caselli \& Wilson, 2004), ${ }^{8}$ we argue that import represents a good proxy of AMT adoption, especially for those countries not characterised by a strong local production for such technologies. Conversely, when local producers account for a substantial share of adoption, the net consumption proxy should provide more precise insights into the phenomenon.

Figure 1 plots values of our two adoption proxies at the beginning and the end of the observation period, showing that import and net consumption are highly correlated, with pairwise correlation coefficients of 0.83 for AIR, 0.78 for AM and 0.66 for IIoT. With the exception of The Netherlands in IIoT, where import is much larger than net consumption, probably due to the export of imported components, import and net consumption largely coincide for all three AMTs. Indeed, the Figure reveals our two measures to be largely comparable across European countries for which we have production data-because the net difference between production and export of AMTs is negligible in the case of most countries and technologies - and import to be an almost perfect measure of adoption.

Despite some differences across the three technologies, this first descriptive evidence suggests that import can be a good proxy of adoption for AMTs across EU countries.

Furthermore, looking at the relative positioning of most EU28 countries in the initial and final year in our sample highlight a proportional change in both import and net consumption proxies. This suggests that the large majority of European countries have been increasingly adopting AMTs. In the following, we argue that this measure indeed captures the patterns of adoption over time and across countries. ${ }^{9}$

\footnotetext{
8 See also Keller (2004) for an extensive review.

9 As a further robustness check, since virtually all European countries in our sample (with the exception of Cyprus, Greece and Malta in the case of AIRs) are also exporters of AMTs-similarly to what found by Caselli and Coleman (2001) in the case of computing equipment already in the mid-90s-we computed import to export ratios for each country and each technology in order to show which countries are net importers of AMTs (ratios above 1) and which countries are exporters of AMTs (ratios below 1). To show the evolution of this dynamics over the observation period we computed initial (2009-2011) and final (2016-2018) three-year averages, to smooth potential peaks in the data. We report this additional analysis in Table B3 in Appendix B. The vast majority of countries in our sample (19 in the case of AM, 20 in the case of IIoT and 14 in the case of AIRs) consistently import more AMTs than they export.
} 

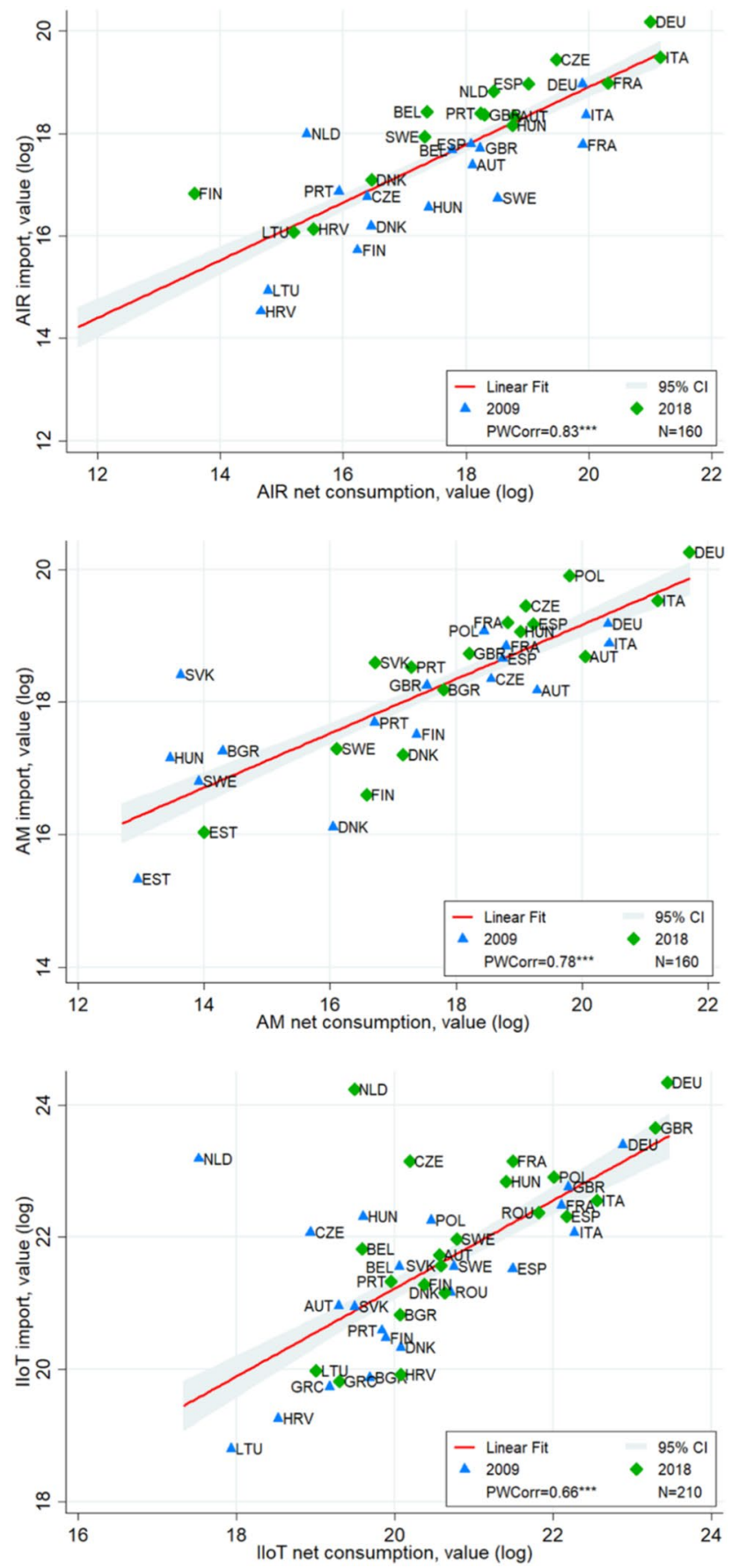

Fig. 1 Relationship between import and net consumption measures of AMT adoption, 2009 and 2018 values and pairwise correlation coefficients. Import and net consumption measures converted in constant PPP USD to increase comparability over time and filter out cross-country differences in prices. Source: Comext and PRODCOM databases 


\subsection{Temporal and geographical patterns of AMT adoption}

As discussed in the previous Sections, these technologies have received considerable attention from businesses and policymakers, and they have been at the core of several industrial initiatives worldwide after the 2009 financial crisis. Hence, we expect the adoption of AMTs across EU28 countries to have significantly increased over our observation period.

Figure 2 explores the change in the flow of import (panel A) and net consumption (panel B) measures between 2009 and 2018, in the aggregate of the European countries for which we have production data (those for which we can compute the net consumption measure). The Figure reports shares of import and net consumption per 1,000 workers to account for differences in country size; we express them as an index $(2009=1)$. Panel A reveals that the adoption of all three AMTs has increased between 1.9 and 2.5 times, with a peak in the import proxy for AIRs that reached a 3.5 -fold increase. The observed pattern looking at the net consumption adoption proxies (panel B) is quite similar, although revealing a more homogeneous growth across the three AMTs, in the aggregate of EU28 countries (i.e. adoption increasing by between 2 and 2.4 times).

Foster-McGregor et al. (2019) highlight that while there has been a rise in the 4IR technologies over the last two decades, the share of these products in total imports remains very small, actually declining over time. To test our measures to this prior finding, Panel C in Fig. 2 reports the shares of the AMT import measures in import of reference benchmark categories. As a benchmark, we use the aggregate of the 2-digit product category(ies) in the $\mathrm{CN}$ classification to which our product codes (for each AMT) belong (i.e. product category 84 for AIRs, the sum of product categories 84 and 85 for AM and the sum of product categories 84,85 and 90 for IIoT). Specifically, here we compare AMT imports with imports of similar and related, yet highly aggregated, goods; this allows to avoid confounding effects due to trends in import flows of goods that are completely unrelated with AMTs. When compared with the product category(ies), we observe that all three I4.0 technologies have experienced a trend of increasing shares of imports over the period 2009-2018 relative to their benchmark, with AIRs increasing from 0.11 to $0.24 \%$ (+114\%), AM imports rising from 0.12 to $0.16 \%$ ( $+36.9 \%$ ) and IIoT increasing from 4.75 to $7.36 \%$ $(+55.1 \%)$.

As an additional robustness check, Fig. 4 in Appendix B replicates the analysis in Fig. 2, but looking at the full sample of all EU28 countries: panel A explores the change in the flow of import measure for our three AMTs between 2009 and 2018, while panel B analyses the trend in the ratio between imports in each AMT and imports of the related benchmark category(ies). Also in this case, as compared to 2009, all three AMTs have increased consistently, with AM and IIoT rising by 1.5 and 2 times, and AIRs even peaking at about 4.9 times. Looking at the share of AMTs in imports of the related benchmarks, the trend is very similar to that observed for the smaller sample of EU countries for which we can compute the net consumption measure, with all AMTs increasing their import components in the benchmark categories (AIRs rising by $126.8 \%$, AM by $36.5 \%$ and IIoT increasing by $53 \%)$. 
Panel A

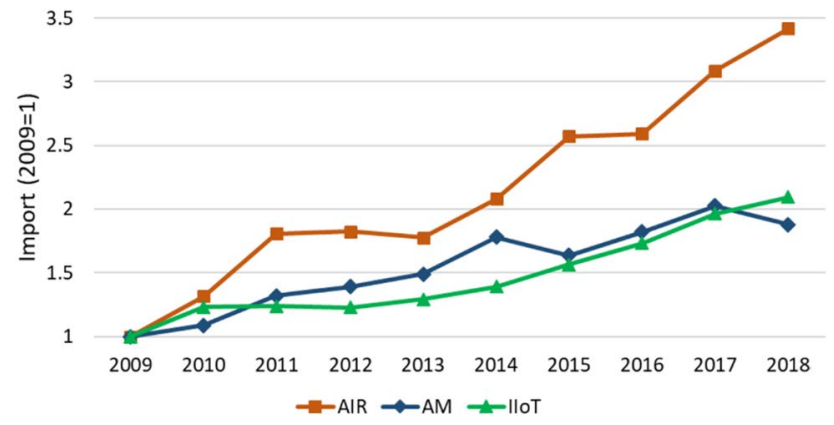

Panel B

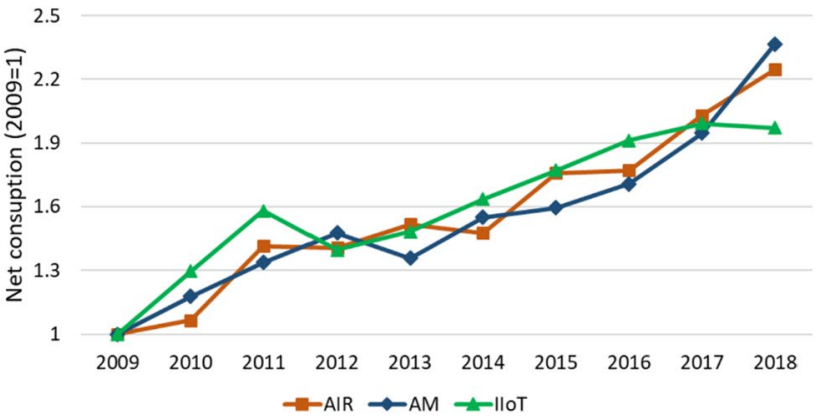

Panel C

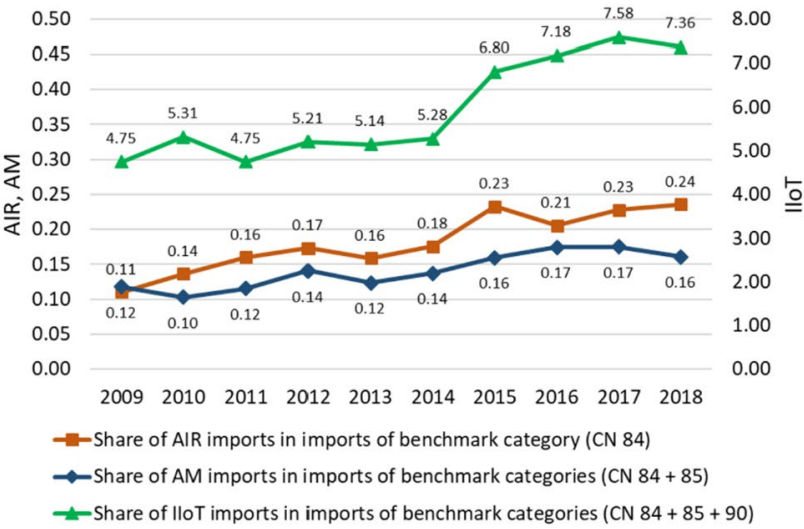

Fig. 2 Change in import and net consumption measures of AMT adoption and shares of AMT imports in imports of the reference benchmark categories (\%)—sample of AMT producers in the EU28 sample, 2009-2018 period. Panel A reports import measures converted in constant PPP USD and reported per 1,000 workers. Panel $\mathbf{B}$ reports net consumption measures converted in constant PPP USD and reported per 1,000 workers. Panel C reports the share of imports of each AMT in imports of the reference benchmark categories (\%); 2-digit benchmark categories are product category 84 for AIR, the sum of product categories 84 and 85 for AM and the sum of product categories 84,85 and 90 for IIoT. Given the high level of aggregation characterising our benchmark product categories in the $\mathrm{CN}$ classification, reconstructing similar benchmark codes from the CPA classification using the methodology presented in Sect. 3 would result in extensive overlapping and the creation of a high number of synthetic codes (resulting from the aggregation of hundreds of 8-digit CPA product codes), in turn not enabling the computation of a precise benchmark. Source: Comext and PRODCOM databases 
To provide further insight, in Appendix B, we analyse the composition of the observed trend for AIRs, AM and IIoT, by looking at the shares of aggregate imports across all EU28 countries in single product codes, included in each of our adoption measures. Specifically, Table 8 reports shares for each year in the observation period and product code composing import measures for AM and IIoT, as well as the observed percentage change between 2009 and 2018 (for AIRs, Table 8 reports the same data presented in panel B of Fig. 4 since the measure includes a single CN/ CPA product code). Such analysis provides insights about some heterogeneity in the trends for individual product codes building our adoption measures, but overall in the vast majority of specific product codes, imports have grown faster compared to the related 2-digit benchmark category(ies), thus leading to an increase in the shares. Specifically, in the case of AM, 5 out of 8 product codes experience an increase in their shares of import (between $+11.8 \%$ and $+84.8 \%$ ), while only 3 product codes experience a slight drop (between $-16.1 \%$ and $-19 \%$ ); similarly, in the case of IIoT, 11 out 13 product codes feature an increase in their share of imports relative to the benchmarks (ranging between $+8.3 \%$ and $+225.7 \%$ ).

Tables 2, 3 and 4 provide detailed data on cross-country differences in the importance of import and net consumption flows per 1,000 workers of AMTs in 2009 and 2018 (AIRs, AM and IIoT, respectively), as well as their growth over this period.

Table 2 shows the import value of AIRs in 2009 and 2018. Among the European countries, we can observe the central role played by Germany, Italy, Sweden, and Austria during the period, although some Central and Eastern European countries (CEECs) such as the Czech Republic, Hungary, Slovakia and Slovenia complete the scenario, by imposing themselves as important players in the adoption of AIRs. ${ }^{10}$ The net consumption data return a very similar picture to the import measure, supporting the strong correlation between the two adoption proxies. Moving to AM, Table 3 shows that the biggest importer is Slovakia, followed by Hungary, the Czech Republic and Slovenia. It is worth highlighting the increasing role of CEECs at the end of the period in the imports of AM, underlining the importance of the adoption of advanced technologies in these transition countries. Among the most advanced and industrialised countries in the EU, Germany and Italy present the highest growth rate of AM adoption. Finally, looking at data for the IIoT adoption proxies in Table 4, we can observe a more widespread adoption, based on both the import and the net consumption data, across Europe. Austria, the United Kingdom (UK), Hungary, Poland, and Romania have registered a substantial increase also in net consumption, representing the major consumers of IIoT at the end of the period.

It is worth noting that among the advanced European economies, the UK registers not only the lowest initial values of adoption across technologies but also lower growth rates in terms of import and net consumption, except for IIoT. On the contrary, countries that report important growth rates over the years are located in Central and Eastern Europe. In particular, these countries emerge as strong AMT adopters not just when looking at our import measure (as one would

\footnotetext{
${ }^{10}$ We suggest caution in the interpretation of values for Cyprus, Malta, and Luxemburg.
} 
Table 2 Import and net consumption of AIRs by European country and growth rates between 2009 and 2018

\begin{tabular}{|c|c|c|c|}
\hline Impor & & & Net cc \\
\hline 2009 & 2018 & Growth rate $(\%)$ & 2009 \\
\hline
\end{tabular}

$\begin{array}{lllll}(1) & (2) & \text { (3) } & \text { (4) }\end{array}$

\begin{tabular}{|c|c|c|c|c|c|c|}
\hline Austria & 9.6 & 22.3 & 133.7 & 19.5 & 35.1 & 79.8 \\
\hline Belgium & 10.9 & 21.5 & 97.7 & 12.0 & 7.4 & -38.3 \\
\hline Bulgaria & 2.5 & 6.1 & 148.8 & & & \\
\hline Croatia & 1.2 & 6.3 & 424.5 & 1.4 & 3.4 & 147.5 \\
\hline Cyprus & 0.6 & 0.0 & -98.2 & & & \\
\hline Czech Republic & 4.0 & 53.9 & 1262.2 & 2.7 & 55.7 & 1950.6 \\
\hline Denmark & 4.3 & 10.2 & 138.6 & 5.6 & 5.4 & -3.6 \\
\hline Estonia & 1.6 & 4.3 & 162.4 & & & \\
\hline Finland & 2.9 & 8.5 & 198.2 & 4.8 & 0.3 & -93.1 \\
\hline France & 2.1 & 6.7 & 226.0 & 17.1 & 25.2 & 47.6 \\
\hline Germany & 4.7 & 14.6 & 211.9 & 11.9 & 33.4 & 180.2 \\
\hline Greece & 0.8 & 1.5 & 86.6 & & & \\
\hline Hungary & 4.2 & 17.6 & 321.9 & 9.6 & 31.7 & 231.3 \\
\hline Ireland & 1.0 & 4.5 & 326.2 & & & \\
\hline Italy & 4.3 & 12.8 & 201.9 & 20.9 & 69.0 & 230.7 \\
\hline Latvia & 1.4 & 2.5 & 76.9 & & & \\
\hline Lithuania & 2.4 & 7.2 & 203.9 & 2.0 & 3.0 & 49.4 \\
\hline Luxemburg & 16.7 & 204.5 & 1123.0 & & & \\
\hline Malta & 6.4 & 3.9 & -38.8 & & & \\
\hline The Netherlands & 8.5 & 18.8 & 121.6 & 0.6 & 12.9 & 1916.0 \\
\hline Poland & 2.2 & 10.9 & 387.6 & & & \\
\hline Portugal & 4.6 & 21.4 & 363.9 & 1.8 & 18.2 & 904.3 \\
\hline Romania & 4.3 & 10.3 & 137.8 & & & \\
\hline Slovakia & 8.0 & 73.6 & 817.4 & & & \\
\hline Slovenia & 5.5 & 35.8 & 556.9 & & & \\
\hline Spain & 2.8 & 9.1 & 221.8 & 3.8 & 9.5 & 150.5 \\
\hline Sweden & 4.3 & 13.0 & 198.6 & 25.7 & 7.0 & -72.9 \\
\hline United Kingdom & 1.8 & 3.1 & 74.7 & 3.0 & 2.9 & -3.3 \\
\hline All Countires Avg & 4.4 & 21.6 & 390.0 & 8.9 & 20.0 & 124.7 \\
\hline
\end{tabular}

Import and net consumption measures converted in constant PPP USD and reported per 1,000 workers Source: Comext and PRODCOM databases

expect), but consistently also when looking at the more precise net consumption proxy for adoption.

In Fig. 3, we further confirm these insights with the cumulated rates of AMT adoption at the end of the period, computed as the stock over the 2009-2018 period per 1,000 workers of both import (left-hand side, in green) and net consumption (right-hand side, in red) measures. Figure 3 shows the coverage and scale, leaders 
Table 3 Import and net consumption of AM by European country and growth rates between 2009 and 2018

$\frac{\text { Import }}{2009 \quad 2018 \quad \text { Growth rate (\%) }}$

Net consumption

(1)

(2)

(3)

$20092018 \quad$ Growth rate (\%)

31.9

Austria

21

Belgium

$13.6 \quad 27.2$

Bulgaria

9.9

27.2

51.7

(4)

(5)

(6)

Croatia

$19.0 \quad 24.8 \quad 30.2$

Cyprus

$\begin{array}{lll}7.9 & 4.4 & -44.5 \\ 19.3 & 54.5 & 183.2\end{array}$

Czech Republic

$\begin{array}{lll}63.6 & 123.7 & 94.5\end{array}$

Denmark

4.0

$\begin{array}{lll}4.0 & 11.3 & 183.5\end{array}$

$\begin{array}{lll}23.7 & 38.8 & 63.6\end{array}$

Estonia

8.0

$8.0 \quad 14.9$

86.1

$3.7 \quad 10.9$

190.7

Finland

17.1

6.7

$-60.5$

$0.7 \quad 1.9$

162.8

France

5.9

$\begin{array}{lll}5.9 & 8.4 & 40.7\end{array}$

Germany

5.8

$\begin{array}{lll}5.8 & 15.9 & 172.3\end{array}$

$14.9 \quad 6.6 \quad-55.5$

Greece

$\begin{array}{lll}10.1 & 10.8 & 7.1\end{array}$

Hungary

$\begin{array}{lll}7.6 & 43.5 & 469.6\end{array}$

Ireland

$5.4 \quad 16.2$

469.6

$5.6 \quad 5.7$

0.9

Italy

$7.2 \quad 13.5$

$16.2 \quad 196.8$

Latvia

88.5

$\begin{array}{lll}11.4 & 33.0 & 188.7\end{array}$

Lithuania

$\begin{array}{ll}11.4 & 33.0 \\ 10.0 & 50.2\end{array}$

401.1

\section{Luxemburg}

27.1

11.0

$-59.4$

Malta

$\begin{array}{lll}15.8 & 4.9 & -68.8\end{array}$

The Netherlands

$\begin{array}{lll}5.5 & 13.8 & 152.6\end{array}$

Poland

12.4

27.7

123.2

$\begin{array}{lll}10.5 & 24.3 & 132.0\end{array}$

$\begin{array}{lll}13.5 & 23.9 & 77.5\end{array}$

Romania

13.5
42.3

$\begin{array}{lll}42.3 & 47.2 & 11.7 \\ 18.8 & 65.8 & 250.1\end{array}$

11.7

$\begin{array}{lll}19.9 & 67.3 & 238.4\end{array}$

Slovakia

Spain

$6.7 \quad 11.3$

67.0

$41.5 \quad 21,835.6$

$\begin{array}{lll}33.5 & 71.1 & 112.1\end{array}$

$\begin{array}{lll}4.6 & 6.8 & 46.4\end{array}$

$\begin{array}{lll}\text { United Kingdom } \quad 3.1 \quad 4.5 & 46.0\end{array}$

All Countires Avg

$12.3 \quad 22.7 \quad 84.6$

\begin{tabular}{lll}
6.6 & 24.8 & 275.4 \\
3.9 & 7.1 & 79.5 \\
& & \\
0.4 & 7.2 & 1940.3 \\
7.3 & 11.8 & 60.8 \\
0.3 & 2.1 & 698.5 \\
1.5 & 2.7 & 76.5 \\
11.7 & 27.5 & 136.4 \\
\hline
\end{tabular}

Import and net consumption measures converted in constant PPP USD and reported per 1,000 workers

Source: Comext and PRODCOM databases

and laggards in the adoption of AMTs in Europe. The graphical representation makes even clearer the role of Central and Eastern Europe (mainly Hungary, Slovakia, and the Czech Republic) as key adopters, followed by Western European countries such as Germany, Italy, Austria, France and Sweden. 
Table 4 Import and net consumption of IIoT by European country and growth rates between 2009 and 2018

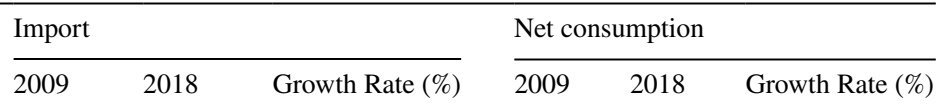

$\begin{array}{lllll}(1) & (2) & \text { (3) } & \text { (4) }\end{array}$

\begin{tabular}{|c|c|c|c|c|c|c|}
\hline Austria & 341.3 & 671.0 & 96.6 & 64.1 & 207.5 & 223.4 \\
\hline Belgium & 526.9 & 644.5 & 22.3 & 118.0 & 69.0 & -41.5 \\
\hline Bulgaria & 134.5 & 360.6 & 168.1 & 111.7 & 170.1 & 52.3 \\
\hline Croatia & 136.9 & 277.7 & 102.9 & 66.1 & 325.9 & 392.9 \\
\hline Cyprus & 94.3 & 166.6 & 76.6 & & & \\
\hline Czech Republic & 798.9 & 2208.9 & 176.5 & 34.7 & 114.7 & 230.3 \\
\hline Denmark & 270.4 & 591.3 & 118.7 & 210.3 & 349.2 & 66.1 \\
\hline Estonia & 332.3 & 1154.2 & 247.4 & & & \\
\hline Finland & 331.3 & 735.6 & 122.0 & 183.5 & 294.2 & 60.3 \\
\hline France & 225.5 & 430.4 & 90.8 & 155.2 & 82.1 & -47.1 \\
\hline Germany & 397.3 & 939.2 & 136.4 & 236.1 & 382.8 & 62.1 \\
\hline Greece & 84.1 & 108.0 & 28.5 & 48.0 & 64.5 & 34.3 \\
\hline Hungary & 1324.6 & 1903.3 & 43.7 & 88.0 & 452.9 & 414.5 \\
\hline Ireland & 626.3 & 824.8 & 31.7 & & & \\
\hline Italy & 173.1 & 276.8 & 59.9 & 211.7 & 277.0 & 30.9 \\
\hline Latvia & 113.2 & 652.8 & 476.6 & & & \\
\hline Lithuania & 113.6 & 361.6 & 218.4 & 47.8 & 137.1 & 186.7 \\
\hline Luxemburg & 742.4 & 528.9 & -28.8 & & & \\
\hline Malta & 4892.0 & 1763.2 & -64.0 & & & \\
\hline Netherlands & 1527.9 & 4224.5 & 176.5 & 5.3 & 36.8 & 590.7 \\
\hline Poland & 297.6 & 555.6 & 86.7 & 49.5 & 225.5 & 355.6 \\
\hline Portugal & 190.6 & 402.2 & 111.0 & 90.2 & 101.6 & 12.7 \\
\hline Romania & 179.4 & 626.0 & 249.0 & 113.1 & 360.9 & 219.0 \\
\hline Slovakia & 534.7 & 929.9 & 73.9 & 124.8 & 344.3 & 175.9 \\
\hline Slovenia & 269.5 & 488.4 & 81.2 & & & \\
\hline Spain & 118.2 & 257.1 & 117.6 & 114.6 & 224.1 & 95.4 \\
\hline Sweden & 541.4 & 728.9 & 34.6 & 240.0 & 221.9 & -7.5 \\
\hline United Kingdom & 281.4 & 624.5 & 122.0 & 159.4 & 434.3 & 172.4 \\
\hline All countires Avg & 557.1 & 837.0 & 50.2 & 117.7 & 232.2 & 97.2 \\
\hline
\end{tabular}

Import and net consumption measures converted in constant PPP USD and reported per 1,000 workers Source: Comext and PRODCOM databases

To provide further insight and robustness to our analysis on the adoption and diffusion of I4.0 technologies, we compute normalised relative import propensity (RIP) 

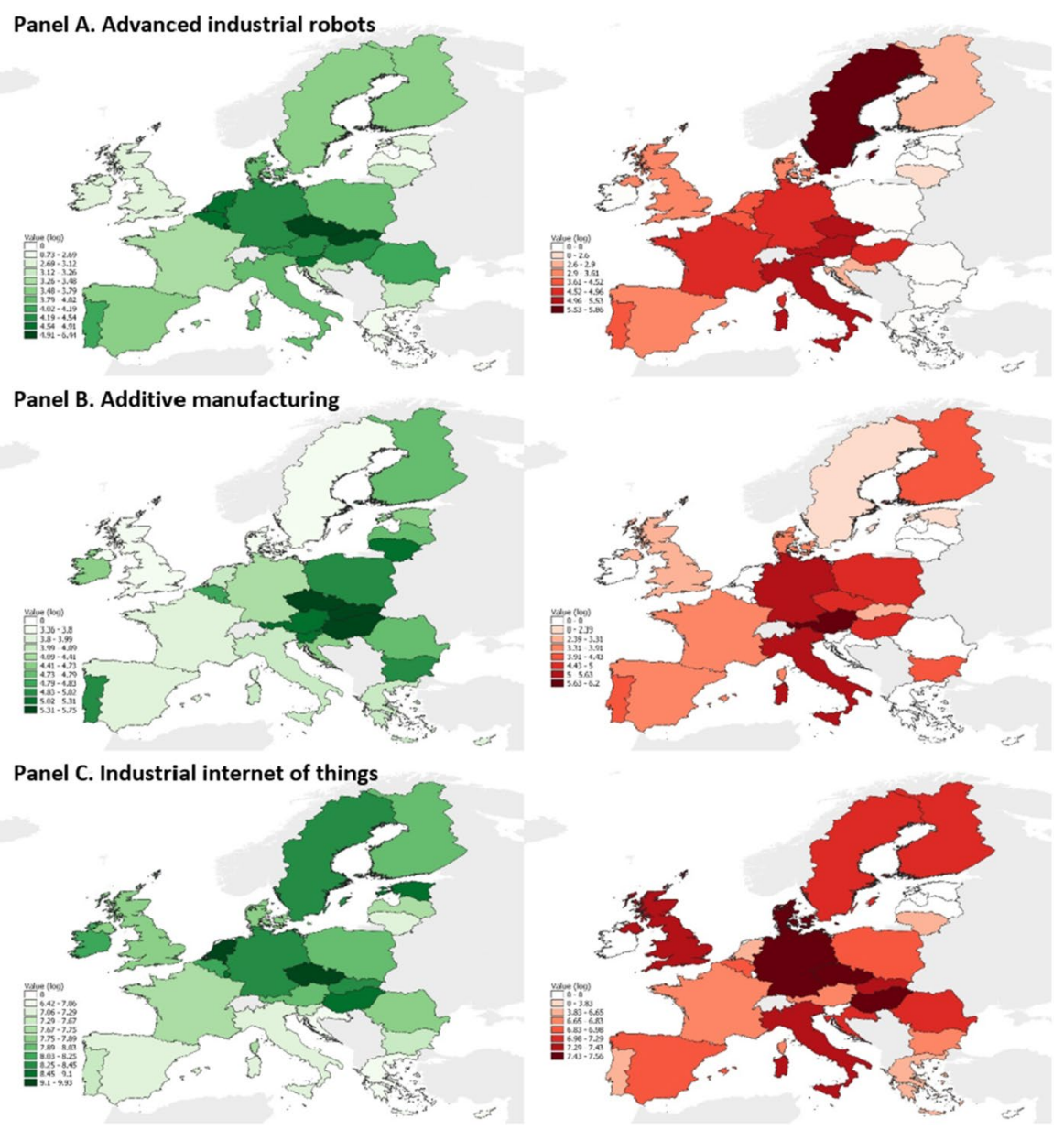

Fig. 3 Import and net consumption of AMTs by EU28 countries, 2009-2018 period stocks. Notes: Import (in green) and net consumption (in red) measures converted in constant PPP USD, reported per 1,000 workers and expressed as 2009-2018 period stocks (in log). Maps created using QGIS software. Source: Comext and PRODCOM databases

indexes ${ }^{11}$ in each country and AMT in our sample, following Foster-McGregor et al. (2019). Such complementary analysis provides insight into the evolution of relative intensity in the adoption of each AMT across EU28 countries, at the beginning and the end of our observation period. Results, which are reported in Fig. 5 in Appendix $\mathrm{B}$, denote remarkable stability in the propensity to import AMTs across countries, but with a handful of countries, mostly among the new member states, that have

\footnotetext{
${ }^{11}$ These indexes are positive (negative) if the share of imports more of a certain AMT in total import of a given country is higher (lower) than the corresponding share in the EU as a whole.
} 
significantly increased their propensity to import AIRs (e.g. Croatia, Czech Republic, Lithuania and Poland) and AM (Hungary).

Two main factors can help explain this pattern. On the one hand, governments of these countries are strongly supporting the investment in the adoption of such game-changing technologies given the industrial composition of their manufacturing industries. For example, the Czech Republic is one of the most industrialised countries, where the automotive industry has an important weight in the industrial composition. ${ }^{12}$ Investing in these technologies is crucial for maintaining the (international) competitiveness of the country and for the long-run economic growth, as part of future innovation strategies and industrial policy objectives (Ministry of Industry \& Trade of the Czech Republic, 2019).

On the other hand, over the last two decades, CEECs have massively strengthened the link with Western European countries through global value chain participation. At the end of 2005, Western European firms were responsible for around $80 \%$ of foreign direct investment (FDI) stock in CEECs, with Germany, Austria, France and Italy accounting for the majority of shares (ECB, 2013). The large-scale investment flow directed from Western European countries towards several CEECs over the last 10-15 years is, in fact, the result of their economic transition from planning and control economies into market economies over the 90s, combined with the benefits of the European Single Market integration policies, as a result of their access to the EU in 2004 (Cséfalvay, 2020). Furthermore, countries like the Czech Republic, Hungary, Slovakia and Poland are the preferred host locations, especially due to their relatively higher political and institutional stability, the availability of relatively skilled workers and the low unit labour costs (Carstensen and Toubal, 2004).

On a complementary perspective, Western European countries are the main destinations of CEEC total exports, $45 \%$ related to foreign value-added or domestic value-added for the exports of other countries, suggesting that their participation in GVCs is mostly associated with western (particularly European) multinational enterprises (ECB, 2013, 2020). A strong interdependence with parent firms allows the transfer of sophisticated machinery and capital goods to local affiliates through imports, able to boost productivity upgrading and develop a domestic industry operated by major productive firms in the sector (Chiacchio et al, 2019). Seen under this light, our evidence points at Europe to be the perfect case to understand how MNEs organize and reconfigure the geographical structure of their supply chains over time-for instance, from global to regional, nearshoring activities in CEECs (Pavlínek, 2018) — and how this can have implications also relatedly to the adoption of new technologies. ${ }^{13}$ Recent evidence from Cséfalvay (2020) on AIRs confirms

\footnotetext{
12 After the global financial crisis in 2009, car manufacturers worldwide started to restructure their business operations, investing heavily in new digital technologies. For instance, since 2010 the automotive industry has witnessed rising investments in new production capacities as well as investments in modern production technologies, resulting in major car-producing countries driving the demand for industrial robots (IFR, 2020).

13 The latest data from Eurostat seems to corroborate our evidence, highlighting that, across European countries, AMT adoption is mostly concentrated in large firms. In 2020, across EU27 countries, only 4\% of small enterprises (10-49 employees) employ AIRs, while this share grows to $23 \%$ among large enterprises $(250+$ employees). Similarly, these shares amount to $4 \%$ and $17 \%$ in the case of AM, to $16 \%$ and $38 \%$ in the case of IIoT, respectively for small and large firms (Eurostat, 2021).
} 
this to be one of the critical factors driving the diffusion of I4.0 technologies across CEECs.

In sum, these findings provide first evidence of the geographical pattern and scale of AMT adoption in Europe: while the most advanced countries have been steadily investing in these technologies in the whole period, we uncover the growing importance of CEECs as I4.0 adopters. At the same time, together with the descriptive statistics provided in Sect. 4.1, our findings provide additional evidence that our import and net consumption measures return consistent results, with the major advantage of the import adoption proxy of being available for an enlarged sample of countries.

\section{Conclusions, future developments and applications}

This paper proposes a fine-grained methodology to measure the adoption of AMTs using trade and production data and provides some descriptive evidence on the patterns of adoption over the last decade across EU countries. Our findings suggest the importance of further investigating the topic and intensifying research efforts to find better, more refined and precise measures able to proxy the adoption of these new technologies. In this respect, the methodology presented in this paper outlines a potential way of overcoming data limitations associated with technologies like AIRs, AM and IIoT. The use of highly disaggregated and detailed trade and production data seems to hold promising opportunities to fill a knowledge gap and offer a powerful tool to investigate how these AMTs are affecting several economic aspects in developed countries, as well as developing countries. Our methodology is easily scalable and can provide up-to-date information on the adoption of AMTs across countries and over time. In particular, considering that the production of AMTs is highly geographically concentrated in a few countries, ${ }^{14}$ in the vast majority of countries imports represent a perfect proxy of adoption. This means that our analysis can be easily extended using 6-digit UN Comtrade data, which are available for all countries in the world and updated regularly to enlarge the sample with non-European countries. Furthermore, while the focus of this paper is at a macro-level, trade data are available at the sector and, increasingly, at the establishment level. Indeed, several statistical offices worldwide are allowing researchers to access detailed import and export data at the transaction level. This opens up the opportunity to build measures of the adoption of AMTs at the firm/establishment level, which so far have been hampered by a chronic lack of information. From a policy perspective, we provide evidence on the adoption and diffusion of AMTs across countries within the European region in a relatively large time window, especially considering countries that are linked through the participation to GVCs orchestrated by western European countries, and the industrial strategies targeting these technologies adopted by

\footnotetext{
14 Our production data indicates that, even within the sample of countries featuring some AMT production (i.e. those reported in the scatterplots in Fig. 1), the large majority of EU production is concentrated in few countries, particularly in the case of AIRs (mostly Austria, Denmark, France, Germany, Italy, Hungary and Sweden) and AM (mostly Austria, Czech Republic, Denmark, Germany, Italy and Slovakia). Conversely, production of IIoT is much more evenly distributed across all EU producers.
} 
CEECs. Data can also provide suggestions and be used to investigate statistically robust causation of the effectiveness of policy incentives put in place to stimulate the adoption of such technologies across countries.

Our effort can provide a set of insights and help define a further research agenda. There are several research areas in the context of I4.0 adoption still under-investigated that can be undertaken using the methodology proposed in this paper.

Productivity, occupation and growth. The transition to a digital economy may boost the competitiveness of a country, create new opportunities for business and entrepreneurial initiatives, as well as a new way to reach international markets, affecting productivity and economic growth as a consequence (UNCTAD, 2017, 2020). The manufacturing sector is still recognised as crucial and remains one of the main drivers of employment and economic growth. For this reason, national and supra-national institutions should devote their effort to incentivising and supporting 'digital development' investments (Davies, 2015; European Commission, 2017), also monitoring the returns and response to incentives already in place. As existing evidence suggests, new digital manufacturing technologies can boost productivity and sustain GDP growth (e.g. Dauth et al., 2018; Edquist et al., 2019; Graetz \& Michaels, 2018). This can be particularly important for emerging economies and their catching-up process, since the adoption of digital technologies may facilitate access to production means and the creation of local (new) enterprises and entrepreneurial initiatives, to contribute to sustainable country development and international competitiveness. However, such technologies can asymmetrically contribute to the growth process, since some countries can have easier access and the ability to use some technologies (e.g. additive manufacturing) rather than others (e.g. advanced industrial robots), due to their peculiar characteristics. Furthermore, these technologies require high-skilled labour (especially with science, technology, engineering, and mathematics (STEM) education). As a form of knowledge-intensive, skill-biased technologies, these could affect occupation, education system, job profile and labour rewards (Frey \& Osborne, 2017). Digitalisation may change jobs, their nature and tasks, the skills required and new jobs may emerge as a result of a digital revolution (Brynjolfsson \& Mitchell, 2017). This may affect the employment patterns and the demand for skills associated with both existing and new jobs (Grundke et al., 2018). Thus, policy interventions should also operate to create the necessary skills and capabilities to promote and support such digital transition, properly mixing economic and social policy actions to balance potentially rising inequality and managerial control over the workforce (Cetrulo \& Nuvolari, 2019).

International business and global value chains. Nowadays, companies require more operational flexibility, reduced time-to-market and closer proximity to their consumption markets to be more responsive to local tastes. This may result in the need of reshaping the organisation of global networks and location advantages toward shorter GVC configurations. The higher capital-intensive nature of these digital and automated technologies can change the landscape of country competitive 
advantages, since the location of manufacturing facilities in low labour-cost countries becomes less and less attractive (Laplume et al., 2016). Besides, these peculiar characteristics may affect the dynamics and drivers of inward/outward FDI, MNEs' internationalisation strategy and location decisions for different value chain activities, and in turn, this may affect GVC organisations (Castellani et al., 2021; Hannibal \& Knight, 2018; UNCTAD, 2017). Following this argument, the adoption of AMTs can incentivize the reshoring of manufacturing operations-i.e. relocation decision back to the firm's home country (Kinkel \& Maloca, 2009; Ellram et al. 2013) - especially when the company aims at increasing its productivity and flexibility (Dachs et al., 2019), or at enhancing the quality of manufactured products, brand recognition and post-sales processes (Ancarani et al., 2019). Thus, sound empirical evidence can help with the development of effective policies and incentives to boost the digital transformation and influence inward and outward FDI flows. In this respect, the intra-firm co-location of production and Research and Development (R\&D) activities is considered crucial to facilitate knowledge transfer across units within the firm's network and to enhance innovation capabilities, especially when the knowledge is tacit and hard to codify (Pisano \& Shih, 2012). However, AMTs can make some knowledge-intensive and production-related research activities more codified and standardised, therefore easy to be transferred across value chain activities and borders. As a consequence, this could affect national and international location and co-location decisions, and the concentration/dispersion of R\&D activities and collaboration across places (Castellani \& Lavoratori, 2020).

COVID-19 and current challenges. The unprecedented disruptions created by the COVID-19 pandemic have strongly challenged businesses across countries and highlighted how sensitive to external shocks particularly dispersed GVCs are, as well as how difficult the management of global organisational structure can be. Recently, the picture has been fuelled by the global shortage of critical components across industries (e.g. semiconductors), and the huge increase in shipping costs per container (Forbes, 2021; UNCTAD, 2021). This has revived the conversation about GVC configurations and more "regionalised" global networks, and how automation and digitalisation can speed such restructuring process, although the sticky nature of GVCs needs to be considered (The Antràs, 2021; Economist, 2020). Furthermore, the COVID-19 shock has caused a "wake-up call" for late digital adopters and the need to start rethinking their operational strategies and business models (Amankwah-Amoah et al., 2021; McKinsey, 2021). Understanding how single AMTs can respond to specific challenges, and whether such technologies can help firms to be more resilient and agile in the long run becomes crucial to create incentives aiming at stimulating timely investment and speeding recovery. Finally, the pandemic has accelerated the call for more environmental-friendly production processes and sustainable manufacturing, where global warming and higher environmental pollution are ascribable to traditional manufacturing technologies, therefore AMTs can play a pivotal role (Bai et al., 2020). In the years to come, rich and 
up-to-date data are necessary to address all these open questions, and trade data can provide invaluable help in this regard.

\section{Appendix A: Data validation}

In order to validate the selection process for the $\mathrm{CN}$ codes reported in Table 1, we consulted a pool of experts composed of both scientists and practitioners, whose expertise relates to the technologies under investigation, as well as to both trade and customs procedures through which $\mathrm{CN}$ codes are assigned to capital goods when they are shipped. Overall, the large majority of the 8-digit codes originally identified were confirmed, hinting at the goodness of the overall identification procedure.

As a first step, we checked if and which product codes are used in practice when goods related to our three AMTs of interest are shipped from their producers to clients worldwide. Clearly, $\mathrm{CN}$ codes-as any other national or international trade classification-are only used when the shipment of goods involves a cross-border transaction. Conversely, domestic transactions are not recorded on trade registers. Bearing this in mind, we created a survey aimed at confirming the 258 -digit $\mathrm{CN}$ product codes matching with our keywords list and collecting information on any other code used in practice. We sent the survey to 229 worldwide producers of industrial robots, additive manufacturing/3D printing machines, and industrial IoT and automation equipment on the 3rd of June 2020, followed by a first reminder sent on the 10th of June and a final reminder on the 17th of June. Respondents were asked to select one or more technologies associated with products in their catalogues and report which $\mathrm{CN}$ codes they use when they export abroad. To maximize the response rate and coverage, as well as provide respondents with the widest range of options, we allowed respondents to choose among other major classifications used in the accounting of both trade and production statistics, alongside the $\mathrm{CN}$ classification. ${ }^{15}$ Unfortunately, despite the response period overlapped with the ease of lockdown measures following the COVID-19 pandemic and with many firms starting back their operations, the response rate was heavily penalised as only $3.5 \%$ of the firms surveyed completed the questionnaire. Nonetheless, the few answers collected allowed us to validate two product codes associated with our AMTs: the 8-digit

\footnotetext{
15 Other trade classifications listed as option were: The Standard International Trade Classification (SITC), the Harmonized System (HS) classification, the Broad Economic Categories (BEC) classification, the U.S. Schedule B number classification, the Japanese Commodity Classification for Foreign Trade Statistics (CCFTS), the Chinese HS classification. Other product classification commonly used in production accounting, listed as option were: the Central Product Classification (CPC), the Statistical Classification of Products by Activity (CPA), the Community Production (PRODCOM) classification, the Austrian OEPRODCOM, the Croatian NIP, the Czech CZ-PRODCOM, the Finnish PRODCOM, the French PRODFRA, the German GP, the Hungarian ITO, the Italian ATECO, the Latvian PRODCOM LV, the Lithuanian PGPK, the Polish PRODPOL, the Romanian PRODROM, the Slovak PRODSLOV, the Slovenian NIP.
} 
$\mathrm{CN}$ code 84795000 covering the trade of industrial robots and the 8-digit Prodcom code 28413471 , corresponding to the CN code 84639000 and supposedly capturing one of the processes related to additive manufacturing. A further takeaway from the survey came from conversations with a few respondents, carried out via email exchange, who highlighted scarce familiarity with the trade and production nomenclatures we suggested as options in the survey.

As a second step, we consulted practitioners and experts working for the Italian Customs Agency (Agenzia delle Dogane e dei Monopoli) and a private customs broker and logistic service provider. ${ }^{16}$ Phone conversations with these experts helped clarify the steps through which $\mathrm{CN}$ product codes are assigned to goods when these transit customs in or outbound. Specifically, goods are classified under a unique classification (e.g. CN, SITC, BEC, etc.) code that describes the product and not its use or specific function. Since incorrect classification can lead to delays in clearing goods, unnecessary overpayment or potential underpayment of duties (the latter resulting in penalties for the shipping firm), this procedure is generally carried out with the highest care and the high majority of firms trading abroad relies on custom brokers to determine the correct product code to be used. In principle, if the shipped good belongs to a very specific category, univocally defined by a product code in the classification adopted, there is little space for errors during the matching procedure. Conversely, in cases where the classification is not up to date with newly developed goods, the identification of the correct product code can suffer from potential misallocations. As custom operators are generally not experts of products, machinery or equipment specificities, when doubts arise, the matching is performed taking the 8-digit product code whose description is the most similar to the in- or outbound good, a more general 6- or 4-digit code, or even the one corresponding to the lowest custom duty among the range of potentially appropriate product codes.

In our specific case, further phone calls with these experts validated other product codes initially selected and associated with our AMTs, upon consultation of private databases to which we could not otherwise get access. Specifically, this second consultation unambiguously validated the selected $\mathrm{CN}$ product code for industrial robots (i.e. 84795000) and several codes presumably related to industrial IoT (i.e. all 8-digit codes shortlisted and included in the 4-digit categories 8471, 8526

\footnotetext{
$\overline{16}$ We contacted the private custom broker and logistic provider Sebi S.r.l. based at the two Milan (IT) airports, Malpensa and Linate.
} 
and 9032), thanks to the high specificity of capital goods associated to these technologies. Furthermore, some procedures were also recorded for the 8-digit code belonging to categories 8517 and 8542, even though only some of them were univocally related to IoT applications. We nonetheless deem these codes validated for the purpose of our investigation, as we are not interested in the actual percentage of matches for each product code in relation to a specific AMT, but rather in confirming that a specific product code was indeed used at least once in trade related to these technologies. From our understanding, the validation of product codes linked to industrial robots and industrial IoT capital goods was possible thanks to the high specificity of good descriptions in both shipment orders and the CN classification, allowing for an unambiguous match in the majority of cases.

The case of additive manufacturing/3D printing machines is relatively more complex as specific $\mathrm{CN}$ product codes do not exist yet (as described above). In this specific case, our phone conversation with the custom experts highlighted a lack of expertise on the technology specificities illustrated in Sect. 2, which guided our initial selection. In turn, only one additional product code associated with additive manufacturing was validated (i.e. CN code 84778099), having got confirmed records of trade of 3D printers under this code. Finally, further conversations with one of the experts also confirmed the potential goodness of the selected 8-digit codes 85158010 and 85158090 upon fit with the specific additive manufacturing process for which they were initially shortlisted, however, we could not get confirmation of any custom practice specifically using these codes in relation to shipments of $3 \mathrm{D}$ printers using powder bed fusion processes (e.g. laser sintering, laser metal deposition, etc.).

\section{Appendix B: Additional Tables and Figures}

See Tables 5, 6, 7, 8 and Figs. 4, 5 


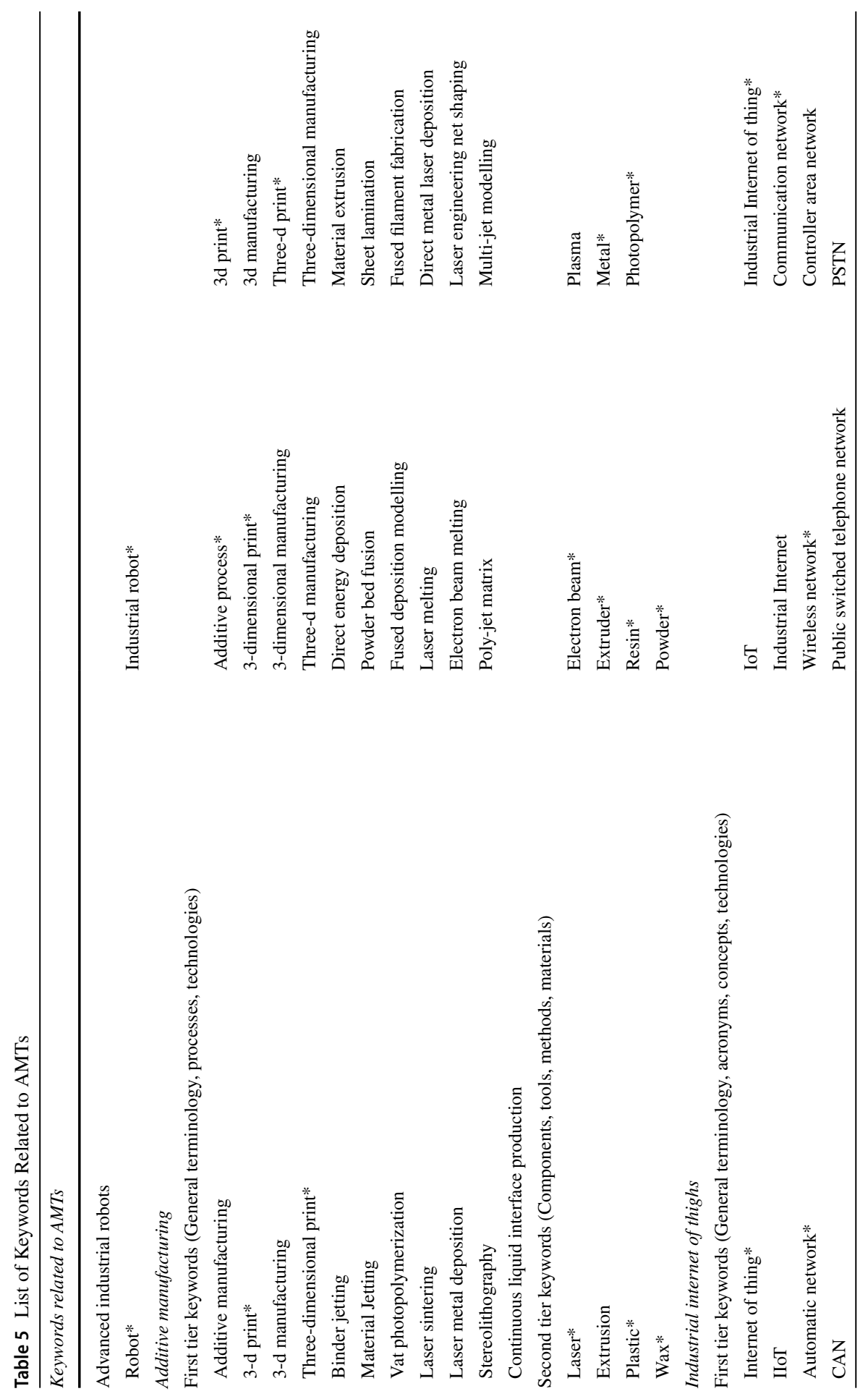




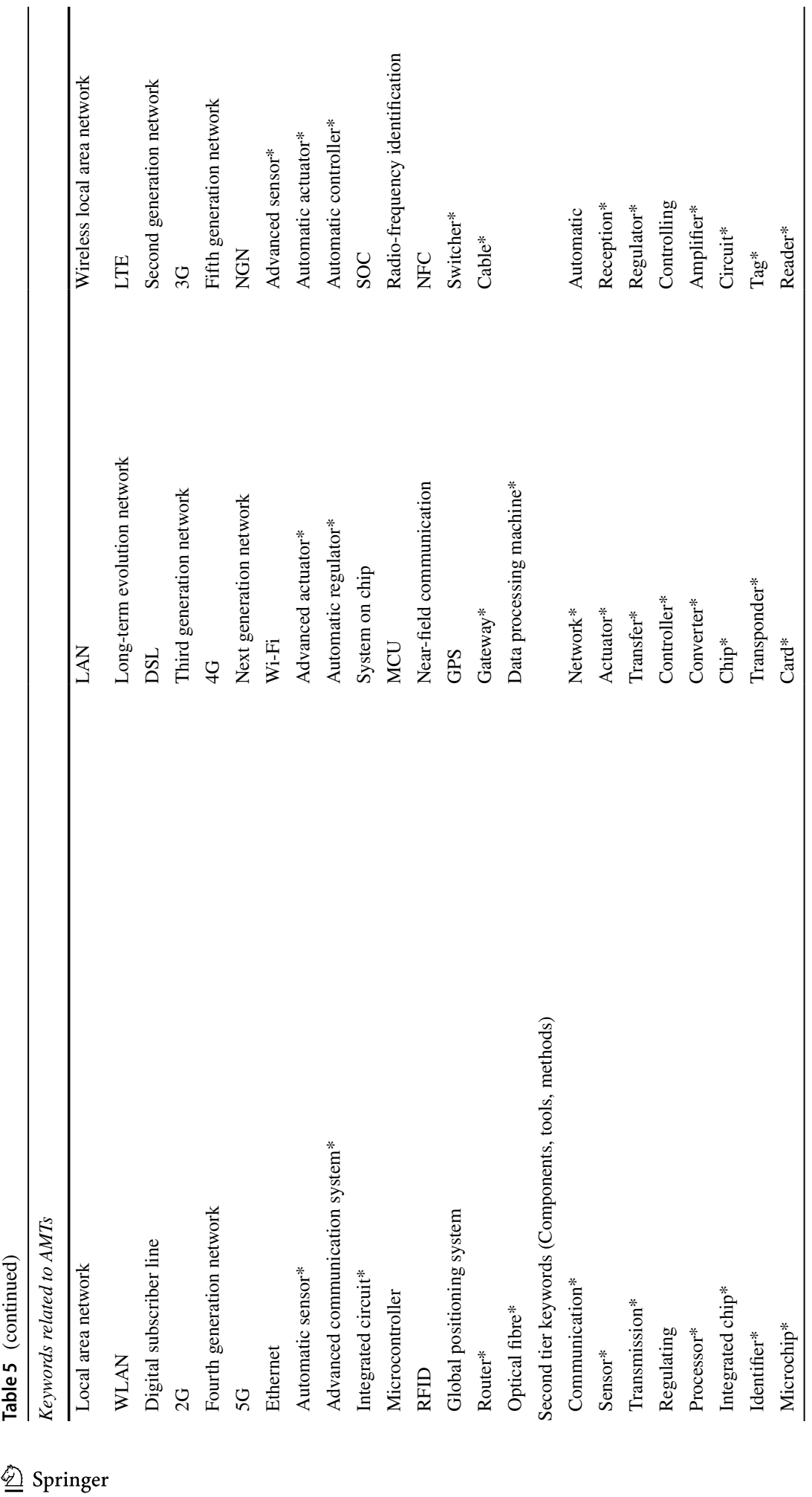




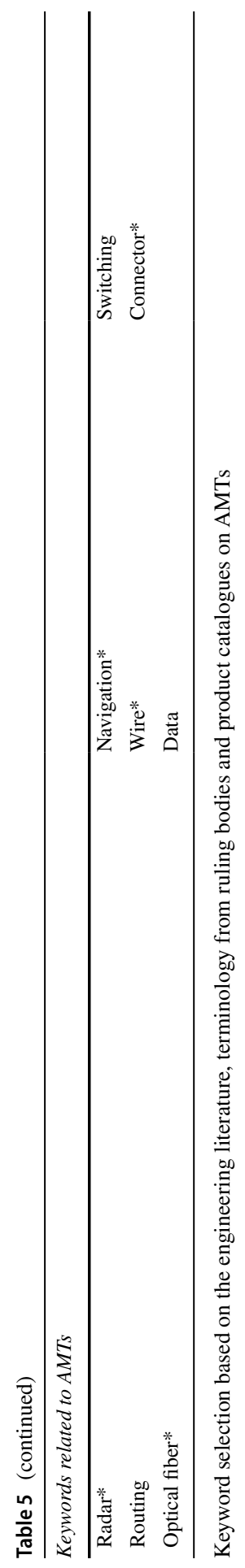




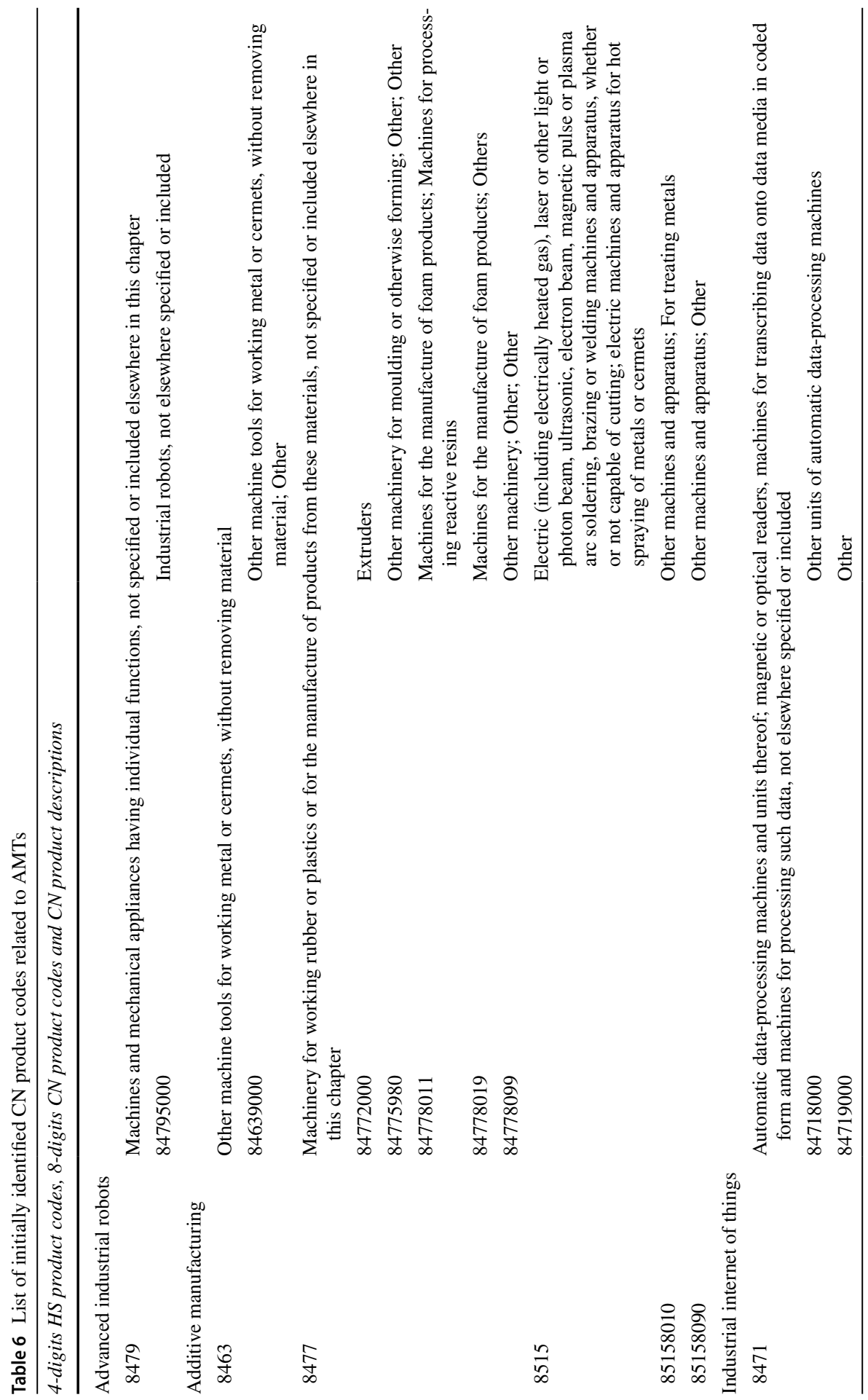




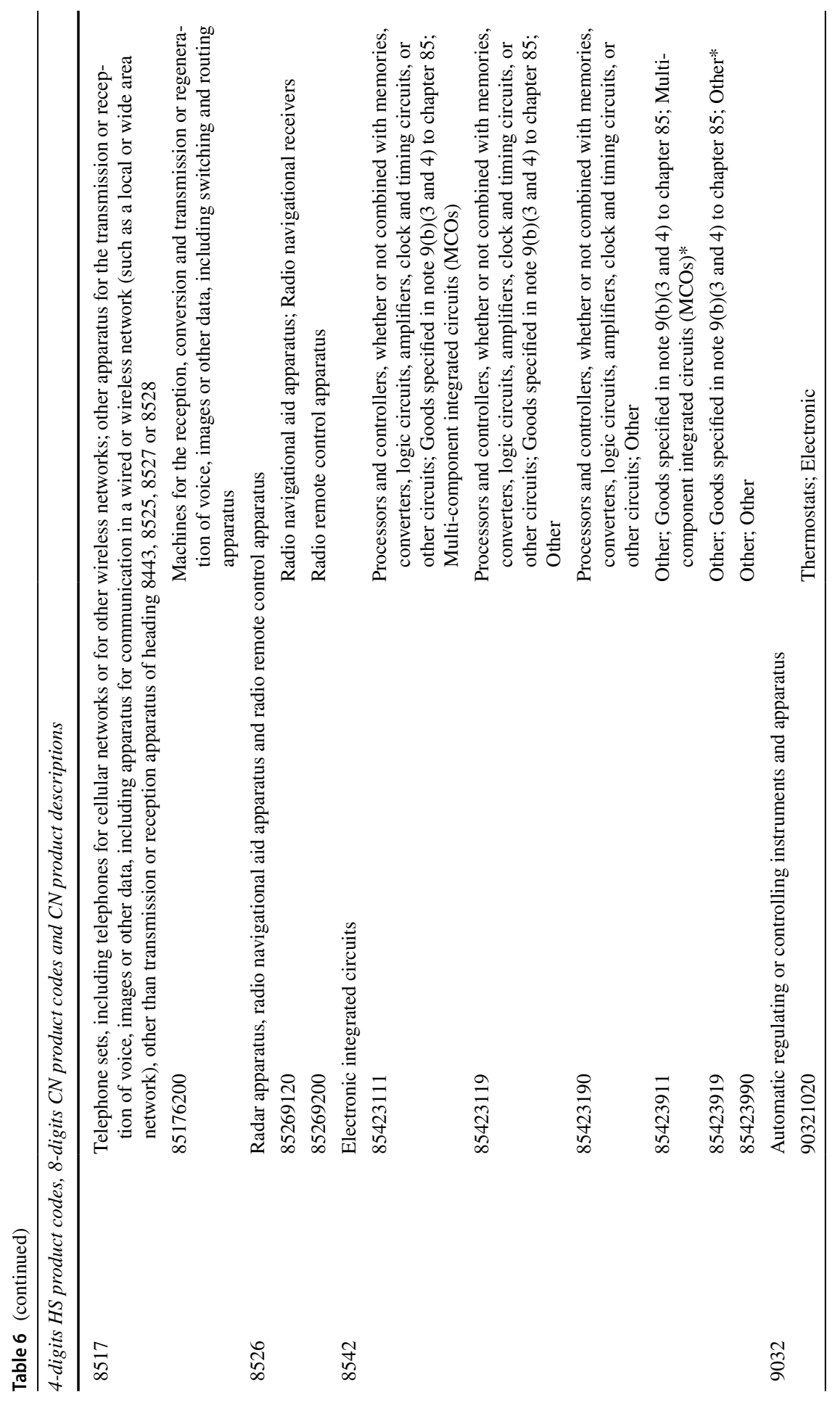




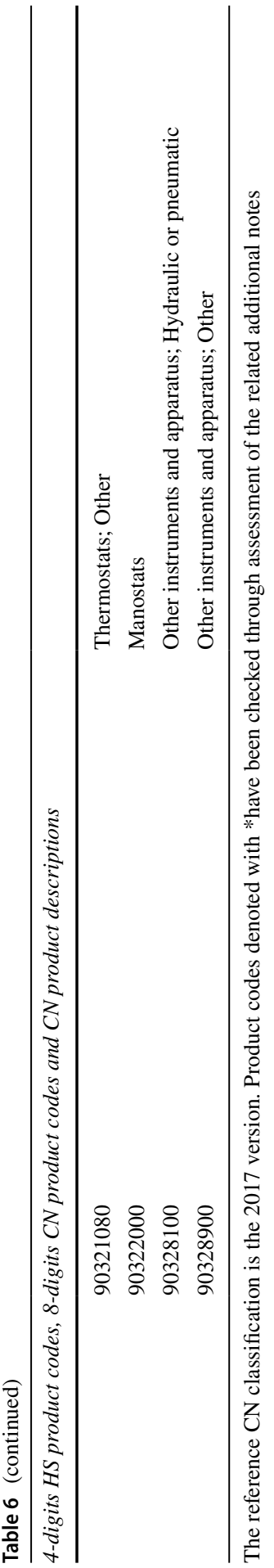


Table 7 Import to export ratios for each AMT, by country and time period

\begin{tabular}{|c|c|c|c|c|c|c|}
\hline & \multicolumn{2}{|l|}{ AIR } & \multicolumn{2}{|l|}{$\mathrm{AM}$} & \multicolumn{2}{|l|}{ IIoT } \\
\hline & 2009-2011 & 2016-2018 & 2009-2011 & 2016-2018 & 2009-2011 & 2016-2018 \\
\hline Austria & 0.51 & 0.44 & 0.45 & 0.24 & 1.06 & 0.93 \\
\hline Belgium & 2.61 & 1.41 & 1.90 & 1.77 & 1.43 & 1.10 \\
\hline Bulgaria & 11.87 & 1.25 & 8.68 & 4.36 & 1.98 & 1.21 \\
\hline Croatia & 9.36 & 0.79 & 2.62 & 0.82 & 1.83 & 2.21 \\
\hline Cyprus & & & 157.50 & 1.35 & 10.14 & 9.59 \\
\hline Czech Republic & 2.39 & 10.72 & 1.42 & 1.08 & 1.28 & 1.38 \\
\hline Denmark & 0.80 & 0.17 & 0.35 & 0.31 & 1.53 & 1.48 \\
\hline Estonia & 3.00 & 2.23 & 2.13 & 5.10 & 1.47 & 0.54 \\
\hline Finland & 0.38 & 0.48 & 1.31 & 2.72 & 1.61 & 1.46 \\
\hline France & 0.60 & 0.42 & 1.10 & 1.15 & 0.98 & 0.88 \\
\hline Germany & 0.64 & 0.61 & 0.12 & 0.15 & 1.01 & 1.05 \\
\hline Greece & & & 5.48 & 2.88 & 5.59 & 4.83 \\
\hline Hungary & 0.66 & 2.21 & 1.86 & 6.64 & 1.29 & 0.92 \\
\hline Ireland & 7.65 & 3.76 & 2.56 & 3.27 & 0.40 & 0.23 \\
\hline Italy & 0.81 & 0.50 & 0.14 & 0.15 & 1.67 & 1.76 \\
\hline Latvia & 4.98 & 2.65 & 2.03 & 1.66 & 1.64 & 0.82 \\
\hline Lithuania & 2.81 & 1.77 & 2.27 & 1.73 & 2.05 & 1.27 \\
\hline Luxemburg & 0.85 & 0.61 & 39.69 & 10.14 & 1.05 & 1.74 \\
\hline Malta & & & 59.73 & 75.58 & 32.16 & 0.47 \\
\hline The Netherlands & 0.99 & 0.73 & 0.73 & 0.76 & 0.91 & 0.91 \\
\hline Poland & 16.80 & 15.94 & 3.50 & 4.16 & 4.44 & 2.08 \\
\hline Portugal & 1.23 & 3.17 & 3.75 & 7.18 & 7.60 & 1.63 \\
\hline Romania & 2.51 & 4.72 & 7.07 & 7.79 & 3.59 & 1.97 \\
\hline Slovakia & 8.63 & 16.02 & 0.67 & 0.55 & 3.61 & 2.16 \\
\hline Slovenia & 3.92 & 2.73 & 1.94 & 1.86 & 1.14 & 1.33 \\
\hline Spain & 1.50 & 1.23 & 1.62 & 2.01 & 4.30 & 2.91 \\
\hline Sweden & 0.21 & 0.29 & 0.71 & 0.99 & 1.26 & 1.31 \\
\hline United Kingdom & 1.54 & 1.09 & 0.88 & 1.35 & 1.42 & 2.17 \\
\hline
\end{tabular}

We compute three-year averages of import to export ratios as simple averages. Ratios above 1 indicates net importers of AMTs, conversely ratios below 1 indicates net exporters of AMTs 


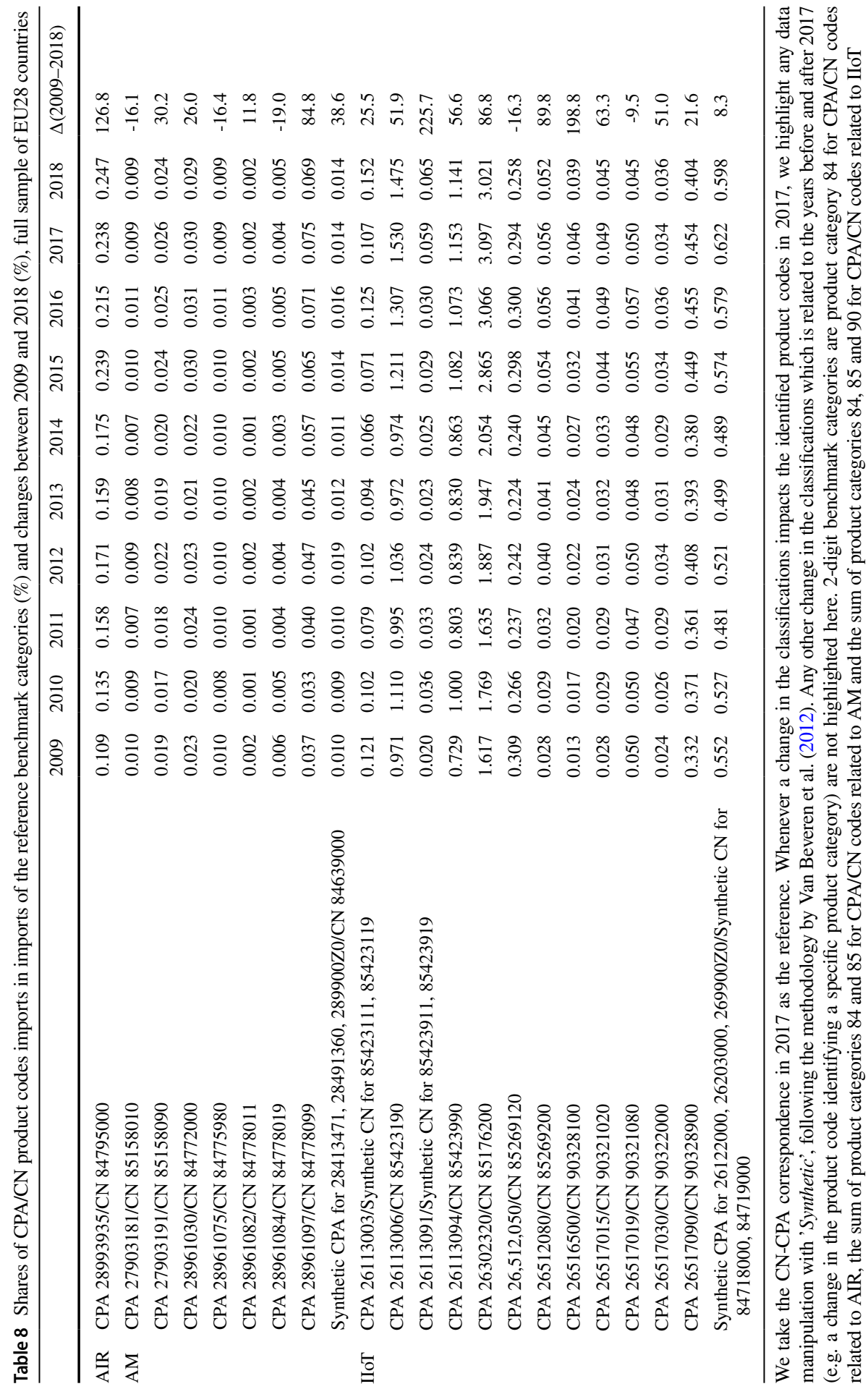



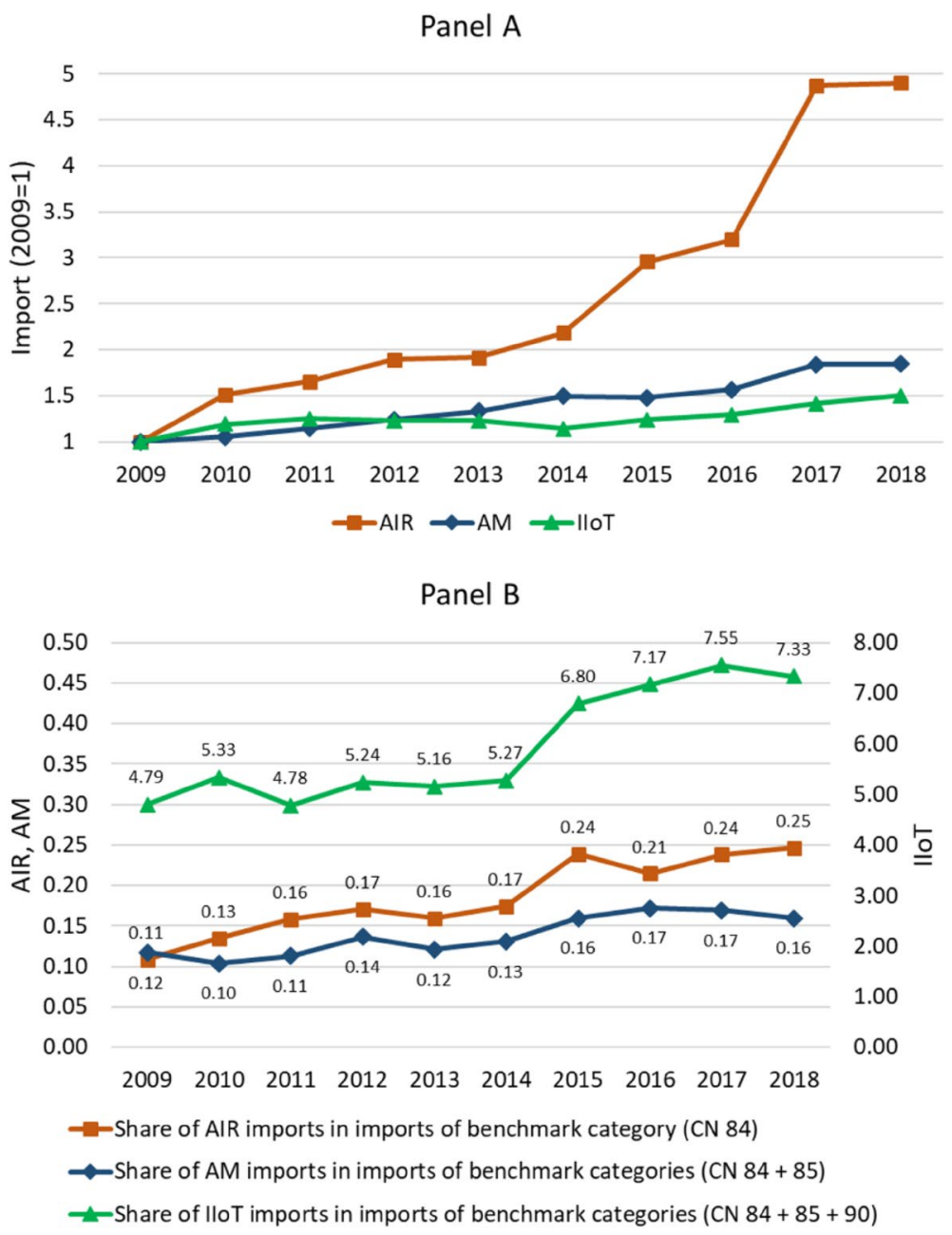

Fig. 4 Change in import measures of AMT adoption and shares of AMT imports in imports of the reference benchmark categories (\%), full sample of EU28 countries, 2009-2018 period. Panel A reports import measures converted in constant PPP USD and reported per 1,000 workers. Panel $\mathbf{B}$ reports the share of imports of each AMT in imports of the reference benchmark categories (\%); 2-digit benchmark categories are product category 84 for AIR, the sum of product categories 84 and 85 for AM and the sum of product categories 84, 85 and 90 for IIoT. Source: Comext database 
Panel A. AIRs

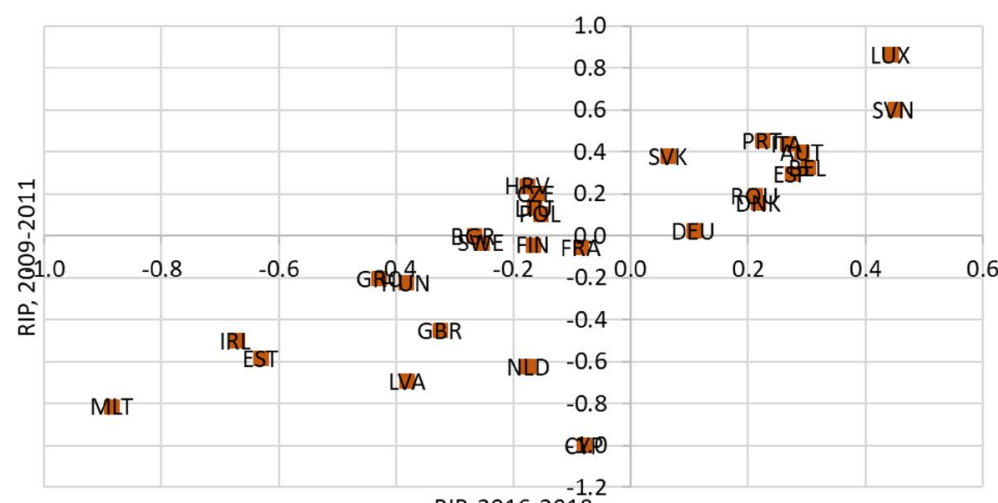

RIP, 2016-2018

Panel B. AM

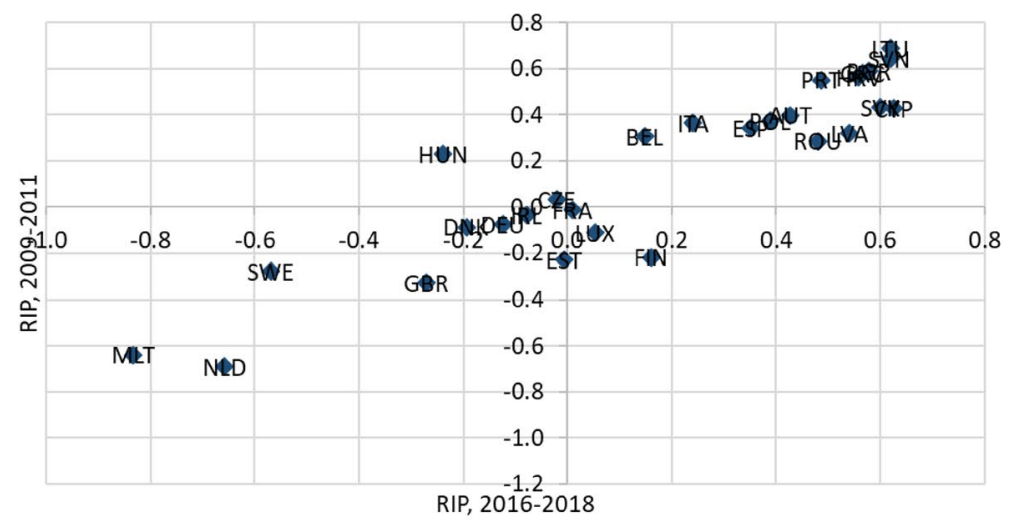

Panel C. IloT

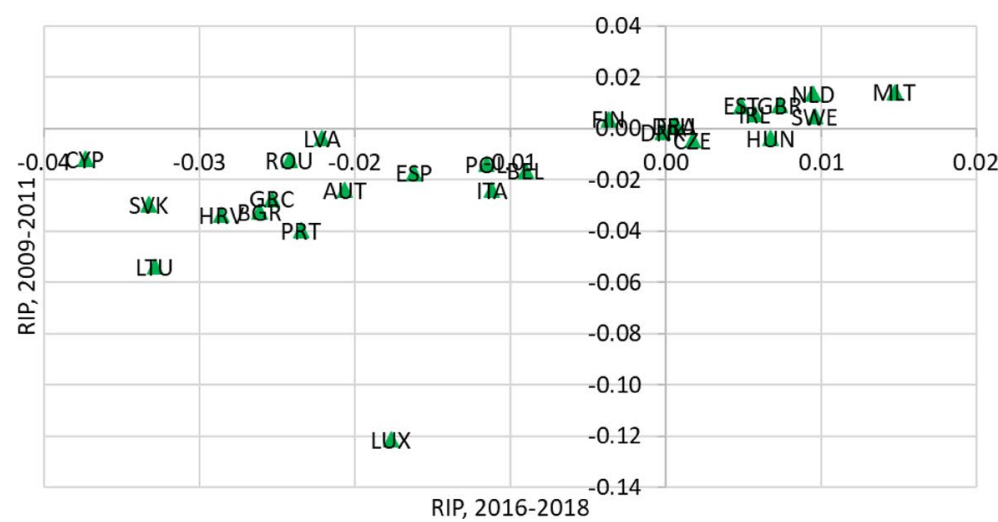

Fig. 5 Comparison between the initial and final three-year averages in the relative import propensity (RIP) indexes for each AMT. We compute three-year averages of RIP indexes as simple averages. RIPs for each AMT are transformed as (RIP - 1)/(RIP + 1) to increase symmetry and comparability so that RIPs above 0 indicates indicate a comparative advantage. Source: Comext database 


\section{Declarations}

Conflict of interest On behalf of all authors, the corresponding author states that there is no conflict of interest.

Open Access This article is licensed under a Creative Commons Attribution 4.0 International License, which permits use, sharing, adaptation, distribution and reproduction in any medium or format, as long as you give appropriate credit to the original author(s) and the source, provide a link to the Creative Commons licence, and indicate if changes were made. The images or other third party material in this article are included in the article's Creative Commons licence, unless indicated otherwise in a credit line to the material. If material is not included in the article's Creative Commons licence and your intended use is not permitted by statutory regulation or exceeds the permitted use, you will need to obtain permission directly from the copyright holder. To view a copy of this licence, visit http://creativecommons.org/licen ses/by/4.0/.

\section{References}

Acemoglu, D., \& Restrepo, P. (2018). Demographics and automation. SSRN Electronic Journal. https:// doi.org/10.2139/ssrn.3138621

Acharya, R. C., \& Keller, W. (2009). Technology transfer through imports. Canadian Journal of Economics/revue Canadienne D'économique, 42(4), 1411-1448. https://doi.org/10.1111/j.1540-5982. 2009.01550.x

Achillas, C., Aidonis, D., Iakovou, E., Thymianidis, M., \& Tzetzis, D. (2015). A methodological framework for the inclusion of modern additive manufacturing into the production portfolio of a focused factory. Journal of Manufacturing Systems, 37(1), 328-339. https://doi.org/10.1016/j.jmsy.2014.07. 014

Amankwah-Amoah, J., Khan, Z., Wood, G., \& Knight, G. (2021). COVID-19 and digitalization: The great acceleration. Journal of Business Research, 136, 602-611. https://doi.org/10.1016/j.jbusres. 2021.08.011

Ancarani, A., Di Mauro, C., \& Mascali, F. (2019). Backshoring strategy and the adoption of Industry 4.0: Evidence from Europe. Journal of World Business, 54(4), 360-371. https://doi.org/10.1016/j.jwb. 2019.04.003

ASTM International. (2013). F2792-12a-Standard terminology for additive manufacturing technologies. Rapid Manufacturing Association. https://doi.org/10.1520/F2792-12A.2

Attaran, M. (2017). The rise of 3-D printing: The advantages of additive manufacturing over traditional manufacturing. Business Horizons, 60(5), 677-688. https://doi.org/10.1016/j.bushor.2017.05.011

Atzeni, E., \& Salmi, A. (2012). Economics of additive manufacturing for end-usable metal parts. International Journal of Advanced Manufacturing Technology, 62(9-12), 1147-1155. https://doi.org/10. 1007/s00170-011-3878-1

Atzori, L., Iera, A., \& Morabito, G. (2010). The internet of things: A survey. Computer Networks, 54(15), 2787-2805. https://doi.org/10.1016/j.comnet.2010.05.010

Bai, C., Dallasega, P., Orzes, G., \& Sarkis, J. (2020). Industry 4.0 technologies assessment: A sustainability perspective. International Journal of Production Economics, 229, 107776. https://doi.org/10. 1016/j.ijpe.2020.107776

Balland, P.-A., \& Boschma, R. (2021). Mapping the potentials of regions in Europe to contribute to new knowledge production in Industry 4.0 technologies. Regional Studies. https://doi.org/10. 1080/00343404.2021.1900557

Bernard, A. B., Grazzi, M., \& Tomasi, C. (2015). Intermediaries in international trade: Products and destinations. The Review of Economics and Statistics, 97(4), 916-920. https://doi.org/10.1162/ REST_a_00495

Brynjolfsson, E., \& McAfee, A. (2014). The second machine age: Work, progress, and prosperity in a time of brilliant technologies. WW Norton \& Company. 
Brynjolfsson, E., \& Mitchell, T. (2017). What can machine learning do? Workforce implications. Science, 358(6370), 1530-1534. https://doi.org/10.1126/science.aap8062

Büchi, G., Cugno, M., \& Castagnoli, R. (2020). Smart factory performance and Industry 4.0. Technological Forecasting and Social Change, 150, 119790. https://doi.org/10.1016/j.techfore.2019.119790

Carstensen, K., \& Toubal, F. (2004). Foreign direct investment in Central and Eastern European countries: a dynamic panel analysis. Journal of Comparative Economics, 32(1), 3-22. https://doi.org/10. 1016/j.jce.2003.11.001

Caselli, F., \& Wilson, D. J. (2004). Importing technology. Journal of Monetary Economics, 51(1), 1-32. https://doi.org/10.1016/j.jmoneco.2003.07.004

Castellani, D., \& Lavoratori, K. (2020). The lab and the plant: Offshore R\&D and co-location with production activities. Journal of International Business Studies, 51, 121-137. https://doi.org/10.1057/ s41267-019-00255-3

Castellani, D., Lavoratori, K., Perri, A., \& Scalera, V. G. (2021). International connectivity and the location of multinational enterprises' knowledge-intensive activities: Evidence from US metropolitan areas. Global Strategy Journal. https://doi.org/10.1002/gsj.1404

Cetrulo, A., \& Nuvolari, A. (2019). Industry 4.0: revolution or hype? Reassessing recent technological trends and their impact on labour. Journal of Industrial and Business Economics, 46(3), 391-402. https://doi.org/10.1007/s40812-019-00132-y

Chekurov, S., Metsä-Kortelainen, S., Salmi, M., Roda, I., \& Jussila, A. (2018). The perceived value of additively manufactured digital spare parts in industry: An empirical investigation. International Journal of Production Economics, 205(87), 97. https://doi.org/10.1016/j.ijpe.2018.09.008

Ciffolilli, A., \& Muscio, A. (2018). Industry 4.0: National and regional comparative advantages in key enabling technologies. European Planning Studies, 26(12), 2323-2343. https://doi.org/10.1080/ 09654313.2018.1529145

Corradini, C., Santini, E., \& Vecciolini, C. (2021). The geography of Industry 4.0 technologies across European regions. Regional Studies. http://dx.doi.org/10.1080/00343404.2021.1884216

Cséfalvay, Z. (2020). Robotization in Central and Eastern Europe: catching up or dependence? European Planning Studies, 28(8), 1534-1553. https://doi.org/10.1080/09654313.2019.1694647

Cuellar, J. S., Smit, G., Plettenburg, D., \& Zadpoor, A. (2018). Additive manufacturing of non-assembly mechanisms. Additive Manufacturing, 21(February), 150-158. https://doi.org/10.1016/j.addma. 2018.02.004

Dachs, B., Kinkel, S., \& Jäger, A. (2019). Bringing it all back home? Backshoring of manufacturing activities and the adoption of Industry 4.0 technologies. Journal of World Business, 54(6), 101017. https://doi.org/10.1016/j.jwb.2019.101017

de Sousa, L., Jabbour, A. B., Jabbour, C. J. C., Godinho Filho, M., \& Roubaud, D. (2018). Industry 4.0 and the circular economy: A proposed research agenda and original roadmap for sustainable operations. Annals of Operations Research, 270, 273-286. https://doi.org/10.1007/s10479-018-2772-8

Delic, M., \& Eyers, D. R. (2020). The effect of additive manufacturing adoption on supply chain flexibility and performance: An empirical analysis from the automotive industry. International Journal of Production Economics, 228(January), 107689. https://doi.org/10.1016/j.ijpe.2020.107689

Diegel, O., Singamneni, S., Reay, S., \& Withell, A. (2010). Tools for sustainable product design: Additive manufacturing. Journal of Sustainable Development, 3(3), 68-75. https://doi.org/10.5539/jsd.v3n3p68

Domini, G., Grazzi, M., Moschella, D., \& Treibich, T. (2020). Threats and opportunities in the digital era: Automation spikes and employment dynamics. Research Policy. https://doi.org/10.1016/j. respol.2020.104137

Edquist, H., Goodridge, P., \& Haskel, J. (2019). The Internet of Things and economic growth in a panel of countries. Economics of Innovation and New Technology, https://doi.org/10.1080/10438599. 2019.1695941

Ellram, L. M. (2013). Offshoring, reshoring and the manufacturing location decision. Journal of Supply Chain Management, 49(2), 3-5. https://doi.org/10.1111/jscm.12023

Felice, G., Lamperti, F., \& Piscitello, L. (2021). The employment implications of additive manufacturing. Industry and Innovation. https://doi.org/10.1080/13662716.2021.1967730

Frey, C. B., \& Osborne, M. A. (2017). The future of employment: How susceptible are jobs to computerisation? Technological Forecasting and Social Change, 114, 254-280. https://doi.org/10.1016/j.techf ore.2016.08.019

Gallab, M., Bouloiz, H., Kebe, S. A., \& Tkiouat, M. (2021). Opportunities and challenges of the industry 4.0 in industrial companies: A survey on Moroccan firms. Journal of Industrial and Business Economics. https://doi.org/10.1007/s40812-021-00190-1 
Graetz, G., \& Michaels, G. (2018). Robots at work. The Review of Economics and Statistics, 100(5), 753-768. https://doi.org/10.1162/rest_a_00754

Gubbi, J., Buyya, R., Marusic, S., \& Palaniswami, M. (2013). Internet of Things (IoT): A vision, architectural elements, and future directions. Future Generation Computer Systems, 29(7), 1645-1660. https://doi.org/10.1016/j.future.2013.01.010

Hannibal, M., \& Knight, G. (2018). Additive manufacturing and the global factory: Disruptive technologies and the location of international business. International Business Review. https://doi.org/10. 1016/j.ibusrev.2018.04.003

Keller, W. (2004). International technology diffusion. Journal of Economic Literature, 42(3), 752-782. https://doi.org/10.1257/0022051042177685

Khorram Niaki, M., \& Nonino, F. (2017). Impact of additive manufacturing on business competitiveness: A multiple case study. Journal of Manufacturing Technology Management, 28(1), 56-74. https:// doi.org/10.1108/JMTM-01-2016-0001

Kianian, B., Tavassoli, S., Larsson, T. C., \& Diegel, O. (2016). The adoption of additive manufacturing technology in Sweden. Procedia CIRP, 40, 7-12. https://doi.org/10.1016/j.procir.2016.01.036

Kinkel, S., \& Maloca, S. (2009). Drivers and antecedents of manufacturing off-shoring and backshoring-A German perspective. Journal of Purchasing and Supply Management, 15, 154-165. https:// doi.org/10.1016/j.pursup.2009.05.007

Laplume, A. O., Petersen, B., \& Pearce, J. M. (2016). Global value chains from a 3D printing perspective. Journal of International Business Studies, 47(5), 595-609. https://doi.org/10.1057/jibs.2015.47

Liao, Y., Deschamps, F., Loures, E. D. F. R., \& Ramos, L. F. P. (2017). Past, present and future of Industry 4.0-a systematic literature review and research agenda proposal. International Journal of Production Research, 55(12), 3609-3629. https://doi.org/10.1080/00207543.2017.1308576

Mariani, M., \& Borghi, M. (2019). Industry 4.0: A bibliometric review of its managerial intellectual structure and potential evolution in the service industries. Technological Forecasting \& Social Change. https://doi.org/10.1016/j.techfore.2019.119752

Martinelli, A., Mina, A., \& Moggi, M. (2021). The enabling technologies of industry 4.0: examining the seeds of the fourth industrial revolution. Industrial and Corporate Change, 30(1), 161-188. https:// doi.org/10.1093/icc/dtaa060

Mellor, S., Hao, L., \& Zhang, D. (2014). Additive manufacturing: A framework for implementation. International Journal of Production Economics, 149, 194-201. https://doi.org/10.1016/j.ijpe.2013.07.008

OECD. (2012). Frascati manual (6th ed.). OECD Publishing.

OECD. (2017). The next production revolution: implications for governments and business. OECD Publishing. https://doi.org/10.1787/f69a68e9-en

Pavlínek, P. (2018). Global production networks, foreign direct investment, and supplier linkages in the integrated peripheries of the automotive industry. Economic Geography, 94(2), 141-165. https://doi. org/10.1080/00130095.2017.1393313

Petrick, I. J., \& Simpson, T. W. (2013). 3D printing disrupts manufacturing: how economies of one create new rules of competition. Research-Technology Management, 56(6), 12-16. https://doi.org/10.5437/ $08956308 \times 5606193$

Sandström, C. G. (2016). The non-disruptive emergence of an ecosystem for 3D Printing-Insights from the hearing aid industry's transition 1989-2008. Technological Forecasting and Social Change, 102, 160-168. https://doi.org/10.1016/j.techfore.2015.09.006

Schwab, K. (2016). The Fourth Industrial Revolution. World Economic Forum.

Singamneni, S., Lv, Y., Hewitt, A., Chalk, R., Thomas, W., \& Jordison, D. (2019). Additive manufacturing for the aircraft industry: A review. Journal of Aeronautics \& Aerospace Engineering, 8, 13. https://doi.org/10.4172/2329-6542.1000214

Skilton, M., \& Hovsepian, F. (2017). The 4th Industrial revolution: Responding to the Impact of Artificial Intelligence on Business. Springer International Publishing AG.

Tuck, C. J., Hague, R. J., Ruffo, M., Ransley, M., \& Adams, P. (2008). Rapid manufacturing facilitated customization. International Journal of Computer Integrated Manufacturing, 21(3), 245-258. https://doi.org/10.1080/09511920701216238

Wang, S., Wan, J., Li, D., \& Zhang, C. (2016). Implementing Smart Factory of Industrie 4.0: An Outlook. International Journal of Distributed Sensor Networks, 12(1), 3159805. https://doi.org/10.1155/ 2016/3159805

Wang, S., Wan, J., Zhang, D., Li, D., \& Zhang, C. (2016b). Towards smart factory for industry 4.0: A self-organized multi-agent system with big data based feedback and coordination. Computer Networks, 101, 158-168. https://doi.org/10.1016/j.comnet.2015.12.017 
Weller, C., Kleer, R., \& Piller, F. T. (2015). Economic implications of 3D printing: Market structure models in light of additive manufacturing revisited. International Journal of Production Economics, 164, 43-56. https://doi.org/10.1016/j.ijpe.2015.02.020

Antràs, P. (2021). De-Globalisation? Global Value Chains in the Post-COVID-19 Age. 2021 ECB Forum: "Central Banks in a Shifting World" Conference Proceedings. Retrieved from https://scholar.harva rd.edu/files/antras/files/deglobalization_sintra_antras.pdf

Benassi, M., Grinza, E., Rentocchini, F., \& Rondi, L. (2020). Going revolutionary: The impact of 4IR technology development on firm performance. SPRU Working Paper Series 2020-08, SPRU - Science Policy Research Unit, University of Sussex Business School. Retrieved from https://www.resea rchgate.net/publication/341186489_Going_Revolutionary_The_Impact_of_4IR_Technology_Devel opment_on_Firm_Performance

Caselli, F., \& Coleman II, W. J. (2001). Cross-country technology diffusion: The case of computers. The American Economic Review, 91(2), 328-335. Retrieved from https://www.jstor.org/stable/2677783

Chiacchio, F., Gradeva, K. \& Lopez-Garcia, P. (2019). The post-crisis TFP growth slowdown in CEE countries: exploring the role of global value chains. Working Paper Series, ECB. Retrieved from https://www.ecb.europa.eu/pub/pdf/scpwps/ecb.wp2143.en.pdf

Craglia, M., Annoni, A., Benczur, P., Bertoldi, P., Delipetrev, P., De Prato, G., \& Tuomi, I. (2018). Artificial intelligence-A European perspective. European Commission, Joint Research Centre. Ispra. https://doi.org/10.2760/11251

Dauth, W., Findeisen, S., Suedekum, J., \& Woessner, N. (2018). Adjusting to robots: Worker-level evidence. Opportunity and Inclusive Growth Institute, Federal Reserve Bank of Minneapolis, (Institute Working Paper 13). https://doi.org/10.21034/iwp.13

Davies, R. (2015). Industry 4.0. Digitalisation for productivity and growth. European Parliamentary Research Service, (September), 10. Retrieved from http:/www.europarl.europa.eu/RegData/etudes/ BRIE/2015/568337/EPRS_BRI(2015)568337_EN.pdf

De Backer, K, DeStefano, T., Menon, C., \& Ran Suh, J. (2018). Industrial robotics and the global organisation of production. OECD Science, Technology and Industry Working Papers 2018/03. OECD Publishing, Paris. http://dx.doi.org/10.1787/dd98ff58-en

De Prato, G., López Cobo, M., Samoili, S., Righi, R., Vázquez-Prada Baillet, M., \& Cardona, M. (2019). The AI techno-economic segment analysis: Selected indicators. European Commission, Joint Research Centre. Seville. https://doi.org/10.2760/576586

Eurofound. (2018). Game changing technologies: Exploring the impact on production processes and work. https://doi.org/10.2806/36769

European Central Bank (ECB). (2013). Monthly Bullettin June 2013. European Central Bank, Germany. Retrieved from https://www.ecb.europa.eu/pub/pdf/mobu/mb201306en.pdf

European Central Bank (ECB). (2020). ECB Economic Bulletin, Issue 1/2020. European Central Bank, Germany. Retrieved from https://www.ecb.europa.eu/pub/economic-bulletin/html/eb202001.en.html

European Commission. (2017). Digital Transformation Monitor-Key lessons from national industry 4.0 policy initiatives in Europe. Retrieved from https:/ec.europa.eu/growth/tools-databases/dem/monit or/sites/default/files/DTM_Policy\%20initiative\%20comparison\%20v1.pdf

European Commission. (2020). Digital innovation hubs helping public sector and SMEs in dealing with COVID-19 pandemic. Retrieved from https://ec.europa.eu/digital-single-market/en/news/digitalinnovation-hubs-helping-public-sector-and-smes-dealing-covid-19-pandemic

European Investment Bank (EIB). (2019). Accelerating Europe's Transformation. Retrieved from: https:// www.eib.org/attachments/efs/economic_investment_report_2019_en.pdf

Eurostat. (2018). Statistics on the production of manufactured goods. Retrieved from Eurostat, the statistical office of the European Union: https://ec.europa.eu/eurostat/cache/metadata/en/prom_esms.htm

Eurostat. (2019). International trade in goods: Metadata. Retrieved from Eurostat, the statistical office of the European Union: https://ec.europa.eu/eurostat/cache/metadata/en/ext_go_agg_esms.htm

Eurostat. (2021). ICT usage in enterprises. Retrieved from Eurostat, the statistical office of the European Union: https://ec.europa.eu/eurostat/web/digital-economy-and-society/data/database

Forbes. (2021). Worsening computer chip crisis shows supply chains are still at risk. Retrieved from https://www.forbes.com/sites/edwardsegal/2021/07/12/worsening-computer-chip-crisis-shows-supply-chains-are-still-at-risk/?sh=35800d2de3da

Foster-McGregor, N., Nomaler, Ö., \& Verspagen, B. (2019). Measuring the Creation and Adoption of New Technologies using Trade and Patent Data. UNU-MERIT Working Papers. Retrieved from https://www.unido.org/api/opentext/documents/download/16411459/unido-file-16411459 
Grundke, R., Marcolin, L., Nguyen, T.L.B., \& Squicciarini, M. (2018). Which skills for the digital era? Returns to skills analysis. OECD Science, Technology and Industry Working Papers, 2018/09, OECD Publishing, Paris. http://dx.doi.org/10.1787/9a9479b5-en

International Federation of Robotics (IFR). (2020). Executive Summary World Robotics 2020 Industrial Robots. Retrieved from https://ifr.org/img/worldrobotics/Executive_Summary_WR_2020_Indus trial_Robots_1.pdf

International Organization for Standardization (ISO). (2015). Additive manufacturing-General principles-Terminology. Retrieved from https:/www.iso.org/obp/ui/\#iso:std:iso-astm:52900:ed-1:v1:en

International Telecommunication Union (ITU). (2012). An overview of internet of things. Retrieved from http://handle.itu.int/11.1002/1000/11559

Kagermann, H., Wahlster, W., \& Helbig, J. (2013). Recommendations for implementing the strategic initiative INDUSTRIE 4.0. In: Final report of the Industrie 4.0 Working Group. Acatech, Frankfurt am Main, Germany. Retrieved from http://alvarestech.com/temp/RoboAseaIRB6S2-Fiat/CyberPhysi calSystems-Industrial4-0.pdf

McKinsey. (2021). COVID-19: An inflection point for Industry 4.0. Retrieved from https://www.mckin sey.com/business-functions/operations/our-insights/covid-19-an-inflection-point-for-industry-40

Ministry of Industry and Trade of the Czech Republic. (2019). National Artificial Intelligence Strategy of the Czech Republic. Retrieved from https://www.mpo.cz/assets/en/guidepost/for-the-media/pressreleases/2019/5/NAIS_eng_web.pdf

Pisano, G.P., \& Shih, W.C. 2012. Does America really need manufacturing? Harvard Business Review, 90(3), 94-102. Retrieved from https://hbr.org/2012/03/does-america-really-need-manufacturing

Rüßmann, M., Lorenz, M., Gerbert, P., Waldner, M., Justus, J., Engel, P., \& Harnisch, M. (2015). Industry 4.0: the future of productivity and growth in manufacturing industries. Boston Consulting Group. Retrieved from https://www.bcg.com/it-it/publications/2015/engineered_products_project_ business_industry_4_future_productivity_growth_manufacturing_industries

Stock, T., \& Seliger, G. (2016). Opportunities of Sustainable Manufacturing in Industry 4.0. Procedia CIRP, 40(Icc), 536-541. https://doi.org/10.1016/j.procir.2016.01.129

The Economist (2020). Less globalisation, more tech. The changes covid-19 is forcing on to business. Apr 11th 2020 edition. Retrieved from https://content.schoolinsites.com/api/documents/279fd20977 d343d4aaa6b09b2c12e84b.pdf

The Guardian. (2020). 10 Covid-busting designs: spraying drones, fever helmets and anti-virus snoods. 25 March, 2020. Retrieved from https://www.theguardian.com/artanddesign/2020/mar/25/10-coron avirus-covid-busting-designs

UNCTAD. (2017). World Investment Report 2017: Investment and the Digital Economy. United Nations Publications, New York. Retrieved from http://unctad.org/en/PublicationsLibrary/wir2017_en.pdf

UNCTAD. (2020). World Investment Report 2020: International Production Beyond the Pandemic. United Nations Publications, New York. Retrieved from https://unctad.org/system/files/officialdocument/wir2020_en.pdf

UNCTAD. (2021). Shipping during COVID-19: Why container freight rates have surged. Retrieved from https://unctad.org/news/shipping-during-covid-19-why-container-freight-rates-have-surged

Van Beveren, I., Bernard, A., \& Vandenbussche, H. (2012). Concording EU Trade and Production Data over Time (NBER Working Paper No. 18604). Cambridge University Press. https://doi.org/10.3386/w18604

Van Roy, V., Vertesy, D., \& Damioli, G. (2019). AI and Robotics Innovation: a Sectoral and Geographical Mapping using Patent Data. GLO Discussion Paper, 433, Global Labor Organization (GLO), Essen. Retrieved from http://hdl.handle.net/10419/209574

Venturini, F. (2021). Intelligent technologies and productivity spillovers: Evidence from the Fourth Industrial Revolution. Retrieved from https://www.researchgate.net/publication/324819823_Intelligent_ technologies_and_productivity_spillovers_Evidence_from_the_Fourth_Industrial_Revolution

World Intellectual Property Organization (WIPO). (2019). WIPO technology trends 2019: Artificial intelligence. Geneva: World Intellectual Property Organization. Retrieved from https://www.wipo.int/ edocs/pubdocs/en/wipo_pub_1055.pdf

Yuk, S. (2018). 2018 WCO Knowledge Academy for Customs and Trade. Session XI: Classification of articles in the HIGH-TECH area. Retrieved from https:/www.eiseverywhere.com/file_uploads/ af31e1d11d64e7916e0a6e0fe78afde0_KACT_2018_HSYukDay3Session_XI_EN.pdf

Publisher's Note Springer Nature remains neutral with regard to jurisdictional claims in published maps and institutional affiliations. 